\title{
LAS PRÁCTICAS LÚDICAS EN UN PARQUE PÚBLICO.
}

\section{RELACIONES ENTRE EL ESPACIO Y EL JUEGO.}

Tesis para Obtener el grado de

Magíster en

Educación Corporal

Profersor: Sergio Monkobodzky

Director: Dr. José Garriga Zucal 


\section{ÍNDICE}

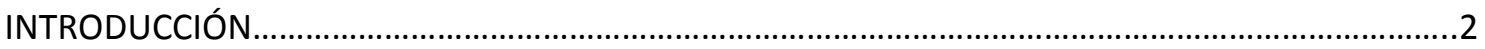

Estado del arte 1: alrededor de los espacios públicos...............................................................

Estado del arte 2: sobre el juego..............................................................................................

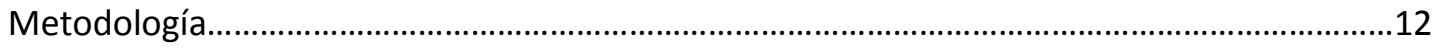

Mapa Lúdico.......................................................................................................................13

\section{CAPÍTULO I: LOS SUJETOS Y EL ESCENARIO DE LAS PRÁCTICAS LÚDICAS}

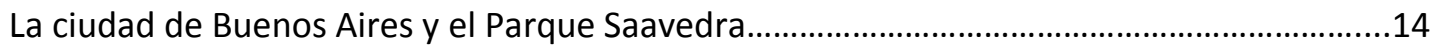

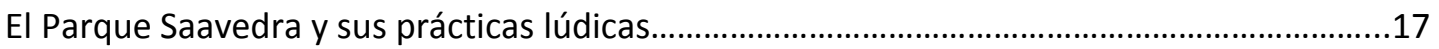

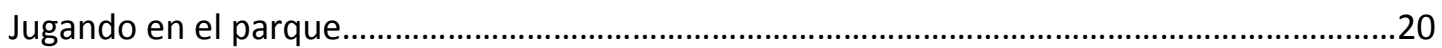

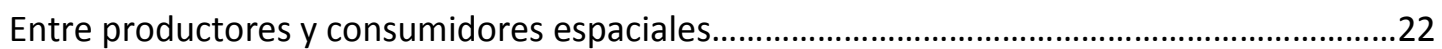

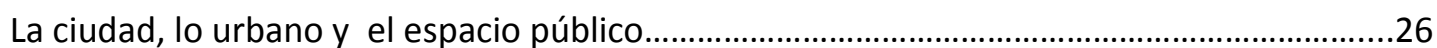

\section{CAPÍTULO II: EL JUEGO DE LOS QUE JUEGAN}

Las prácticas lúdicas realizadas por los sujetos en forma sistemática

desde una perspectiva del juego.

Las prácticas lúdicas realizadas por los sujetos en forma no sistemática

desde una perspectiva del juego................................................................................................

Eligiendo el juego................................................................................................................

Sobre las diferencias entre los jugadores.............................................................................48

\section{CAPÍTULO III: EL ESPACIO DE LOS QUE JUEGAN}

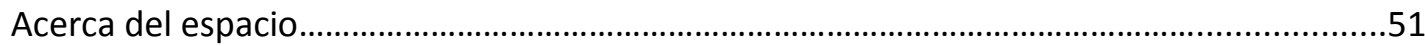

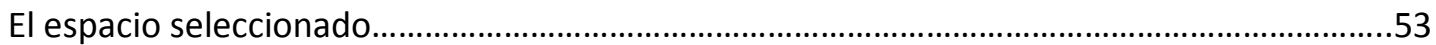

Las prácticas lúdicas realizadas por los sujetos en forma sistemática

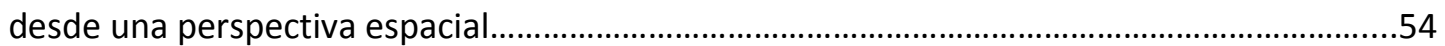

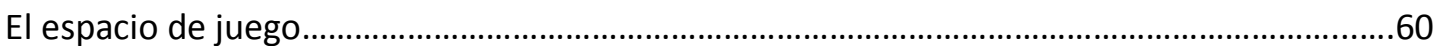

Las prácticas lúdicas realizadas por los sujetos en forma no sistemática

desde una perspectiva espacial............................................................................................61

La elección espacial....................................................................................................................63

CONCLUSIONES

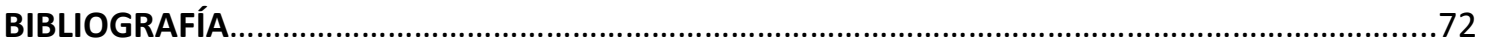




\section{INTRODUCCIÓN}

En los parques públicos de una ciudad se suceden diversas prácticas culturales. Para muchos sujetos éstos son el escenario de numerosas y diferentes prácticas lúdicas. Esta tesis estudia la relación entre las prácticas lúdicas y el espacio donde se realizan. Proponemos en esta investigación revelar, algunas dimensiones del siempre complejo vínculo entre espacio y juego, tomando como referente empírico un parque público.

Los primeros interrogantes surgieron al observar cómo numerosos sujetos se reunían en un parque público a realizar sus prácticas lúdicas. Distintos grupos, heterogéneos en tanto a edades y género, llegaban al parque, elegían un espacio y efectuaban su juego. Sin disputas por la asignación del espacio jugaban en una armonía que parecía el resultado de una meticulosa organización.

Al observar este tipo de prácticas nos surgieron varios interrogantes, especialmente dos para destacar: ¿por qué los sujetos eligen un espacio y no otro para efectuar sus prácticas lúdicas? y ¿por qué los sujetos eligen un determinado juego y no otro para realizar en el parque?

Empezamos entonces a preguntarnos cómo y cuánto el espacio determina o condiciona las prácticas lúdicas posibles. Por ello definimos que se podía realizar una investigación de las prácticas lúdicas abordando el espacio y el juego. Fue así que se construyó la pregunta que motorizó nuestra investigación: ¿qué relación existe entre prácticas lúdicas y espacio en un parque público? Para ello iniciamos un relevamiento de las prácticas lúdicas en un parque para investigar la relación entre juego y espacio. A través del análisis de las prácticas lúdicas en el Parque Saavedra descubrimos que existía una relación entre los espacios elegidos y el tipo de juego elegido. Aquellas prácticas que se repetían sistemáticamente utilizaban siempre las mismas zonas del parque $y$, por el contrario, aquellas prácticas que no eran recurrentes se realizaban aleatoriamente.

Para comprender la relación entre espacio y juego se realizó un recorrido que comprendió tres postas. En el primer capítulo se realizó un abordaje descriptivo y conceptual sobre los espacios urbanos, en general, y los parques públicos, en particular. Se incluyó en este recorrido: la urbe, el barrio y el parque público, soportes 
esenciales del proceso de construcción de identidad de los sujetos. En el inicio de este primer capítulo se realizó una caracterización de la Ciudad de Buenos Aires, el barrio Saavedra y los parques públicos. Luego se presentó el barrio Saavedra con sus particularidades y su historia para contextualizar, localizar y caracterizar al Parque Saavedra, escenario de la investigación. Se enunciaron las prácticas lúdicas realizadas por los sujetos en forma sistemática y en forma no sistemática, prácticas que se convirtieron en el foco de esta investigación. También se abordó la tensión existente entre los productores del espacio público y los consumidores del mismo desde una perspectiva lúdica. Y por último se explicitó la diferencia conceptual entre la ciudad y lo urbano y la consideración del espacio público.

El segundo capítulo comenzó con un registro de los sujetos que arribaron al parque con el juego seleccionado a priori y otros sujetos que concurrieron al mismo sin haber seleccionado a priori su juego. Luego se realizó un diálogo de autores cuyas conceptualizaciones utilizamos para analizar y reflexionar sobre las prácticas lúdicas realizadas por los sujetos en forma sistemática y en forma no sistemática. Indagamos, luego, cómo abordaban los sujetos la elección de sus juegos. Establecimos diferencias entre los jugadores que ya tenían seleccionado su juego a priori y los sujetos que llegaron al parque sin haberlo elegido. Al finalizar este capítulo concluimos que: las prácticas lúdicas que realizaban los sujetos en forma sistemática, es decir aquellas que tenían por lo menos una repetición semana a semana, coincidían con las prácticas lúdicas efectuadas por los sujetos que ya habían elegido a priori su juego. Del mismo modo se pudo considerar que coinciden generalmente las prácticas lúdicas ejecutadas por los sujetos en forma no sistemática, o sea, que no se registró una reiteración de la misma en una unidad de tiempo semanal, con las prácticas realizadas por los sujetos que arriban al parque sin haber elegido su juego a priori.

En el inicio del tercer capítulo se presentó un diálogo de autores cuyas concepciones utilizamos para analizar y reflexionar sobre los espacios de las prácticas lúdicas. Luego en función del espacio seleccionado se consideraron las prácticas lúdicas realizadas por los sujetos en forma sistemática y las prácticas lúdicas realizadas por los sujetos en forma no sistemática. Distinguimos que hubo sujetos que arribaron al Parque Saavedra, con el espacio elegido a priori para efectuar sus prácticas lúdicas y otros agentes sociales, que concurrieron sin haber elegido a priori el espacio para 
realizar sus prácticas lúdicas. Una vez señaladas las diferencias entre ambas situaciones, concluimos que, desde un enfoque espacial, coincidieron las prácticas lúdicas efectuadas en forma sistemática por los sujetos en el parque con la elección a priori del espacio donde los agentes sociales realizaron sus prácticas lúdicas. Y comprobamos que, generalmente, coincidieron los sujetos que realizaron las prácticas lúdicas en forma no sistemática con los sujetos que arribaron al parque sin haber elegido a priori el espacio donde efectuaron sus prácticas.

Considerando el juego y el espacio utilizado, orientamos las conclusiones a establecer una relación entre los sujetos que realizaron sus prácticas lúdicas en forma sistemática y la elección a priori de la llegada al Parque Saavedra. Por otro lado establecimos que lo sujetos que realizaron sus prácticas lúdicas en forma no sistemática arribaron al parque sin haber seleccionado a priori su juego y el espacio donde efectuarlo.

\section{Estado del arte 1: alrededor de los espacios públicos}

Para la investigación sobre los espacios públicos consideramos como referencia la antropología urbana propuesta por Delgado Ruiz (2002), quién analizó la diferencia entre lo urbano y la ciudad. El autor señala que la antropología de lo urbano se colocaría en la misma tesitura que pretende ocupar la antropología del espacio: una visión cualitativa de éste, de sus texturas, de sus accidentes y regularidades, de las energías que en él actúan, de sus problemáticas, de sus lógicas organizativas. Continúa diciendo Delgado Ruiz (2002) que la antropología del espacio ha sido casi siempre una antropología del espacio construido, es decir del espacio habitado. A diferencia de lo que sucede con la ciudad, lo urbano no es un espacio que pueda ser morado. La ciudad tiene habitantes, lo urbano no. Lo urbano está constituido por usuarios. Por ello, el ámbito de lo urbano por antonomasia, su lugar, es, no tanto la ciudad en sí misma como su espacio público.

Cedeño Perez (2005) señala que los parques públicos urbanos se pueden considerar espacios libres verdes, áreas abiertas no edificadas destinadas a usos colectivos diversos. O como espacios públicos de dimensiones significativas y predominio de elementos naturales, principalmente cobertura vegetal, destinados a la recreación. En 
su tiempo libre una parte de la población utiliza los parques y plazas como escenario de sus prácticas lúdicas.

Para esta investigación se consideró al parque público formando parte de lo urbano. Los espacios verdes no tienen moradores ni habitantes sino sujetos que lo visitan para disfrutar su tiempo libre. Según Delgado Ruiz (2002) es en el espacio público donde se produce la epifanía de lo que es específicamente urbano: lo inopinado, lo imprevisto, lo sorprendente, lo absurdo. La urbanidad consiste en esa reunión de extraños, unidos por la evitación, la indiferencia, el anonimato y otras películas protectoras, expuestos, a la intemperie, y al mismo tiempo, a cubierto, camuflados, mimetizados, invisibles. El espacio público es vivido como espaciamiento, esto es como espacio social regido por la distancia.

Según De Certau, Girad, Mayol (1999), frente al conjunto de la ciudad saturada de códigos que el usuario no domina pero que debe asimilar para poder vivir en ella, frente a una configuración de lugares impuestos por el urbanismo, el usuario logra crearse lugares de repliegue, itinerarios para su uso o su placer que son las marcas que ha sabido imponer al espacio urbano. Ambos autores hacen referencia a lo urbano. Delgado Ruiz (2002) expone que es en el espacio público dónde se dan las características de esa reunión de extraños marcados por la indiferencia y el anonimato. De Certau, Girad, Mayol (1999) ponen énfasis en las respuestas de los usuarios, creándose lugares de repliegue para su uso o placer. Delgado Ruiz (2002) sostiene que el espacio como fundado y constantemente refundado se opone a cualquier cosa que pudiera parecerse a los puntos identificatorios, relacionales e históricos: el plano, el barrio o cualquier otro enclave, los límites del pueblo, la plaza pública con su iglesia, el santuario o el castillo, los monumentos históricos, asociados todos ellos a un conjunto de potencialidades, de normativas y de interdicciones sociales que tienen como tema común la domesticación del espacio. De Certau, Girad, Mayol (1999) afirman que el barrio es un dominio del entorno social pues es para el usuario una porción conocida del espacio urbano en la que más o menos se sabe reconocido. El barrio se puede entender como esa porción del espacio público en general dónde se insinúa poco a poco un espacio privado particularizado debido al uso práctico cotidiano de ese espacio. El límite público - privado, que parece ser la estructura fundadora del barrio 
para la práctica del usuario, constituye una separación que une: no se puede entender en el contexto barrial el significado de uno sin el otro.

Desde la psicomotricidad analítica Calmels (2001) diferencia entre el espacio geométrico y el espacio habitado. El primero remite al espacio posible de ordenar en categorías, formas y medidas y el segundo se refiere al espacio de apropiación subjetiva. Bachelard (2012) sostiene que el espacio habitado trasciende el espacio geométrico. Ambos autores destacan la existencia de diferentes tipos de espacios. De Certau, Girad, Mayol (1999) explicitan que, en el barrio y en mayor medida en cada hábitat, cada sujeto puede hacer lo que desee. Calmels (2001) distingue el espacio geométrico del espacio habitado. Diferencian las formas y medidas de la apropiación subjetiva. El concepto de espacio vacío se utilizó en el abordaje de los sujetos que realizaron sus prácticas lúdicas y que en función de su frecuencia de concurrencia fueron tomando pertenencia grupal y a su vez una preferencia espacial, configurando un territorio propio.

Delgado Ruiz (2002) sostiene que la calle y la plaza son, en este sentido, objetos de un doble discurso. Uno es resultado de un diseño urbanístico y arquitectónico políticamente determinado, cuya voluntad es orientar la percepción, ofrecer sentidos prácticos, distribuir valores simbólicos $y$, al fin $y$ al cabo, influenciar sobre las estructuras relacionales de los usuarios del espacio. Un segundo discurso es el de la sociedad urbana misma, en el sentido de la sociedad de los urbanitas: no de los habitantes de la ciudad, sino de los usuarios-productores de lo urbano. Son ellos quienes tienen siempre la última palabra acerca de cómo y en qué sentido moverse físicamente en el seno de la trama propuesta por los planificadores. Coincidiendo con Delgado Ruiz (2002) se consideró el pensamiento de De Certeau (1996) en lo referido al binomio conceptual de sujetos productores y sujetos consumidores.

De Certeau (1996) realiza un aporte interesante en su investigación sobre las prácticas de los consumidores. Aquellas prácticas casi silenciosas por la cual los actores se apartan de distintas maneras de lo que los productores planifican y organizan. Los consumidores, dominados pero no pasivos ni dóciles, ponen su acento en realizar lo que le dicen pero aportando su propio significado.

En relación al Parque Saavedra, se tuvo en cuenta para esta investigación la oposición entre los productores de los espacios, diseñadores del parque y los sujetos 
en su rol de usuarios. Se colocó el foco en el arte de hacer ${ }^{1}$ de los usuarios, que generalmente realizaban sus prácticas lúdicas en espacios que no fueron construidos especialmente para ellos. Los consumidores del espacio no respetaban los usos para los que fueron diseñados.

Una de las miradas de esta investigación colocó el foco en los sujetos que asistían al parque en forma sistemática para realizar sus prácticas lúdicas. Se orientó la observación para registrar indicios del proceso por lo cual los sujetos usuarios de las prácticas lúdicas iban conformando su territorio, es decir construían un proceso por el cual pasaban del anonimato a una identidad grupal. Delgado Ruiz (2002) señala que el espacio público es un territorio desterritorializado, que se pasa el tiempo siendo reterritorializado y vuelto a desterritorializar, marcado por la sucesión y el amontonamiento de componentes, en que se registra la concentración y el desplazamiento de las fuerzas sociales que convoca o desencadena y que está crónicamente condenado a sufrir todo tipo de composiciones y recomposiciones. Es desterritorializado también porque en su seno lo único de veras consensuado es el desinterés mutuo y porque constituye un espacio en que nada de lo que concurre y ocurre es homogéneo: un espacio esponjoso en el que casi nada merece el privilegio de quedarse. Lo que pasa allí, es lo que el investigador ha optado por conocer.

Las prácticas lúdicas registradas en el Parque Saavedra están inscriptas en lo urbano, en el espacio público utilizado por los usuarios de la ciudad. Colocamos uno de los focos de esta investigación en los grupos que concurrieron al parque y que a partir de sus prácticas lúdicas sistemáticas (se encuentran por lo menos una vez por semana) fueron protagonistas de un proceso de territorialización. Orientamos también la mirada hacia aquellos sujetos que asistieron en forma no sistemática al parque para efectuar sus prácticas lúdicas y que son considerados sujetos de paso, como los transeúntes de lo urbano.

\footnotetext{
${ }^{1}$ Esta expresión fue tomada del subtítulo del libro La Invención de lo cotidiano de Michael De Certau
} (1996) 


\section{Estado del arte 2: Sobre el juego.}

El juego es un término polisémico, ya que posee una pluralidad de significados que en muchos casos son contarios entre sí. Se han realizado varios esfuerzos para definir este término pero sin grandes resultados. Sutton Smith ${ }^{2}$ declaró que en su Asociación para el estudio del juego han "discutido interminablemente durante 15 años cuál es la distinción entre juegos, pasatiempos y deportes sin llegar a una respuesta satisfactoria" (1991: 35). Varios autores, entre ellos Huizinga (2007), ya en 1938, expresaba que las diversas teorías sobre el juego son muy diferentes pero que de ningún modo se excluyen entre sí.

Así se puede considerar que el juego es complejo:

-porque incluye al universo de todos los sujetos, ya que comprende al hombre y a la mujer desde su nacimiento hasta la tercera edad pasando por la infancia, adolescencia y juventud.

-porque si se considera la historia de la humanidad se comprueba que el juego ha estado y sigue estando presente en la vida cotidiana de los sujetos.

-porque incluye tanto al género femenino como al masculino.

-porque aborda situaciones que refieren a estratos conscientes e inconscientes de los sujetos.

El juego es un término polisémico, ya que posee una pluralidad de significados que en muchos casos son contarios entre sí. En la lengua cotidiana puede expresar una juego de herramientas, (serie de elementos), juego entre dos piezas (articulación entre elementos), juegos de luces, de colores (combinación de elementos), etc. También puede señalar distintos y muy variados tipos de juegos: juegos de mancha, escondida, juegos con pelota, juegos de cartas, juegos de ingenio. En el campo de la educación física la palabra juego tiene diferentes jerarquías: puede designar una teoría del juego, puede ser el nombre de una unidad en una planificación o puede significar simplemente una actividad para realizar con un grupo. Resumiendo se considera la

\footnotetext{
${ }^{2}$ Citado en Sutton Smith B (1996) Notas hacia una crítica de la teoría de juego psicológica del siglo veinte. En Homo ludens. El hombre que juega 1. Buenos Aires, Instituto para la investigación del juego y la pedagogía del juego.
} 
acción de jugar trasciende a la palabra juego y deja de pertenecer exclusivamente a este significado.

Según Corominas (1973) citado en Navarro Adelantado (2002) el vocablo juego procede del latín vulgar Jocus y significa broma, chanza, diversión ${ }^{3}$. Otra referencia en latín menciona su procedencia de la voz latina ludus-ludere que expresa juego infantil, recreo, competición, juegos públicos, juegos de azar, representación teatral. En la evolución del vocablo juego hubo un traspaso del ludus al jocus que se realiza trasladando el contenido de su significado más el concepto de broma, diversión de la situación carente de seriedad. Se le fueron agregando otros usos pero actualmente el juego-jugar está sustentado sobre el núcleo del significado original. Por lo tanto, el juego-jugar mantiene dos rasgos fundamentales con el paso del tiempo: la acción de jugar y la diversión-recreación. Más allá de otros vocablos, que aparecen en forma tardía como: ludere, jocus, entretenerse, recreación, el juego-jugar es el significado más profundo de una acción característica y fácilmente identificable.

\section{ESTA CONCEPCIÓN DE JUEGO SERÁ TOMADA EN ESTA INVESTIGACIÓN}

La concepción de juego de este trabajo de investigación se abordó desde una perspectiva social y cultural. Se consideró que el juego está influido por el entorno social y el ámbito histórico en el cual se desarrolla y que sus acciones tienen estrecha relación con las ideas y formas de organización de los grupos y sociedades.

El abordaje se realizó desde una perspectiva que toma al juego como productor de cultura. Uno de los autores principales de referencia es Johan Huizinga. En su libro Homo Ludens señaló que: "El juego es más viejo que la cultura, pues, por mucho que estrechemos el concepto de ésta, presupone siempre una sociedad humana, y los animales no han esperado a que el hombre les enseñara a jugar" (2007: 11). Agrega el

\footnotetext{
3 La palabra juego posee varios significados si se toma como referencia el diccionario de la Real Academia Española (2001): acción y efecto de jugar; ejercicio recreativo sometido a reglas, y en el cual se gana o se pierde por ejemplo: juego de pelota, de ajedrez, de billar, etc....

Según el diccionario de María Moliner (1990) la palabra juego tiene también varias acepciones: acción de jugar; cualquier clase de ejercicio que sirve para divertirse; conjunto de acciones que con sujeción a ciertas reglas se realizan como diversión; lugar de juego; prácticas de los juegos de azar; etc. Ambos diccionarios enuncian en primer lugar: la acción de jugar. Se considera a este significado como el más genuino y el más preciso para la palabra juego.
} 
autor holandés que a través del juego, esencialmente los juegos de competición, los pueblos manifiestan su interpretación de la vida y del mundo.

Huizinga (2007) expone en su libro varias definiciones acerca del juego. Para esta investigación la definición que se consideró como punto de partida fue:

el juego es una acción u ocupación libre que se desarrolla dentro de unos límites temporales y espaciales determinados según reglas absolutamente obligatorias libremente aceptadas, acción que tiene un fin en sí misma y va acompañado de tensión y alegría y da la conciencia de ser "de otro modo" que en la vida corriente" (2007: 45).

En sus investigaciones sobre el juego y los juegos Caillois (1958) critica a Huizinga por su concepción demasiada amplia, ya que con el juego intenta explicar toda la historia y la cultura, y a la vez por su enfoque muy reducido sobre el juego ya que considera solo los juegos de competición reglamentada. Caillois (1958) propone una clasificación para abordar el universo del juego: los juegos con predominio de la competición (agón) como el fútbol, las canicas o el ajedrez, los juegos con predominio del simulacro (mimicry) donde se juega a hacer de pirata, de Maradona o de Hamlet, los juegos con predominio del azar (alea) como la lotería, la ruleta y los juegos con predominio del vértigo (ilinx).

La clasificación de Caillois (1958) no comprende por entero el universo del juego. Lo distribuye en cuadrantes donde se puede hacer referencia del predominio de una característica del juego sobre otra. El autor agrega dentro de esta clasificación en cada cuadrante un ordenamiento en base a dos polos antagónicos: paidia y ludus. El primero es un principio común de diversión, de turbulencia, de libre improvisación y de despreocupada alegría por donde se manifiesta una cierta fantasía incontrolada. El segundo es por el contrario un principio de diversión con la necesidad de someterlo a convenciones arbitrarias e imperativas.

Según Gerlero (2004), las actividades cercanas al ludus no son patrimonio exclusivo de un grupo de jugadores, se convierten en una práctica social. Las reglas, elementos esenciales de los juegos, son acordadas por los jugadores; se orientan hacia el polo del ludus configurándose un mayor control de los impulsos del juego a través de reglas 
que provienen del contexto social. En algún momento estos juegos se comienzan a repetir en su estructura y son parte del bagaje cultural de un grupo social.

Para abordar también el juego se tuvo en cuenta el pensamiento de Pavía (2006) tomando el juego desde la perspectiva del jugador. El investigador argentino, desde su perspectiva, pone énfasis en el jugador y dice que su estudio abarca el juego con acción directa del cuerpo, con reglas explícitas y donde hay una cierta acción, un guión dramático, un como si. Agrega que el juego es como "una mentira" con complicidad de los jugadores y que posee libertad, placer y especialmente emoción, característica priorizada por él en sus investigaciones. Pavía (2006) sostiene que se puede llamar juego a toda situación observada donde los jugadores dicen que es juego.

Asimismo, el autor señala que abordar el estudio del juego es como desentrañar los secretos de un ovillo de lana. A medida que se lo desenreda para penetrar en sus secretos el objeto se va disolviendo hasta quedar solo la lana, es decir, los jugadores y el sentido que éstos le adjudican a una acción identificada por construcción histórica, social y cultural con el nombre genérico de juego. Pavía (2006) configura una restricción al mundo lúdico para explicitar ciertas consideraciones que son esenciales para su enfoque del juego. Así el juego “...implica algún grado de compromiso corporal, con un componente de actuación en el contexto de la regla" (2006: 40). Agrega luego como características esenciales sobre el juego: "cuerpo y movimiento", "contexto de reglas", "fingimiento auténtico" y "sesgo autotélico".

Pavía (2006) señala dos conceptos importantes para la comprensión del juego: la forma y el modo. La forma se refiere al orden estricto de la actividad, el juego como sustantivo. Es la apariencia singular de un juego específico. Es la forma lo que diferencia un juego orientado al fútbol de un juego orientado al voley; lo que distingue jugar a golpear una pelota con paletas de lanzar un disco de plástico. La forma está más vinculada a la actividad, en cambio el modo está relacionado con el sujeto. Pavía, en relación con el mundo de la gramática, define al modo "...como la manera particular que adopta el jugador de ponerse en situación de juego, de acoplarse a la actividad propuesta" (2006: 42). La libertad de elección recibe la influencia del contexto social e histórico. La mutua influencia entre el sujeto y su contexto posibilita la aparición de un modo lúdico producto de la reproducción social y sus diferentes matices. 
Parlebas afirma que "El espacio material representa el soporte irrecusable de todo juego" (1988: 119). Definir un juego es en parte, establecer las características de los lugares donde se realiza: dimensiones y normas, naturaleza y consistencia (materiales artificiales, elementos de plena naturaleza).

Pavía (2005) sostiene que la atención sobre lo recreativo estuvo centrada principalmente sobre la actividad que se realizaba y que el análisis de la perspectiva espacial ocupó un segundo plano. En esta investigación se abordó, también, la temática de los espacios seleccionados por los sujetos para realizar sus prácticas lúdicas.

\section{Metodología}

Adoptamos una modalidad cualitativa para realizar el abordaje de la investigación, por ello, realizamos la recolección de datos a través de la observación. Como nos interesaba qué se jugaba y dónde nos propusimos observar la distribución espacial y la elección lúdica. Queda para otro trabajo posterior la indagación de los motivos de estas elecciones desde el punto de vista de los jugadores. En esta etapa nos interesaron los usos del espacio en relación a la elección de los juegos. Por ello se realizó una primera etapa exploratoria donde se confeccionó un registro de las prácticas lúdicas. Los períodos de observación fueron discontinuos, comenzando a fines del año 2006 y se continuó durante el año 2007. Al año siguiente se relevaron los cambios producidos por una remodelación que se realizó en el parque. La construcción de nuevas sendas asfaltadas modificó usos y costumbres de algunos grupos que concurrían al parque. El trabajo de campo finalizó a principios del 2009 cuando concluyeron las obras ejecutadas. Los días sábados y domingos se realizaron la mayor cantidad de observaciones, ya que estos días resultaron ser los de mayor concurrencia. A partir de los datos obtenidos se seleccionaron las prácticas lúdicas que fueron base de esta investigación. Resolvimos circunscribir la mirada de las prácticas lúdicas realizadas por los sujetos a un sector del parque (ver mapa lúdico). Esta decisión se tomó debido a la gran extensión del mismo.

Tuvimos, también, que recortar nuestro objeto en dos dimensiones. Por un lado realizamos una primera delimitación, desde un aspecto etario, consistió en focalizar 
estas prácticas en sujetos mayores de 5-6 años. Por otro lado, se restringió el mundo lúdico a los juegos que implicaron algún grado de compromiso corporal, priorizándose los que se realizaban con elementos. Así, de los juegos observados no se tuvieron en cuenta los juegos de azar, considerando la clasificación sobre los juegos de Caillois (1958).

\section{Mapa Lúdico}

Confeccionamos un registro de las prácticas lúdicas realizadas por los sujetos en forma sistemática. Ubicamos en un mapa del Parque Saavedra la posición de los grupos observados. (Foto № 1)

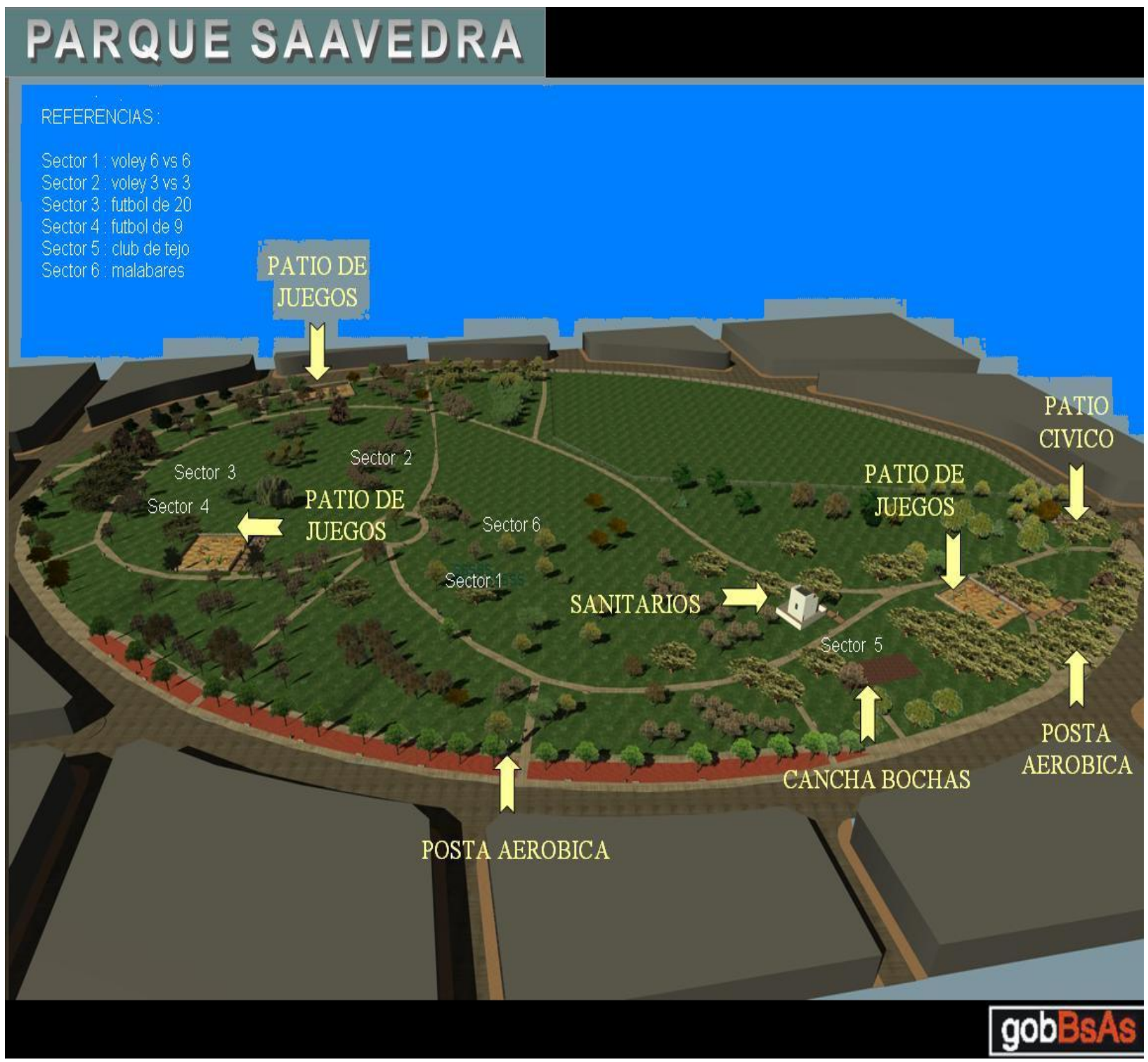

Foto № 1. Mapa lúdico 


\section{CAPÍTULO I}

\section{EL ESCENARIO DE LAS PRÁCTICAS LÚDICAS}

\section{La ciudad de Buenos Aires, el barrio Saavedra y los parques públicos}

Las ciudades se caracterizan por su alta densidad de población. Concentran en general el poder político, económico y social de la región donde están ubicadas. En nuestro país la ciudad autónoma de Buenos Aires cumple con estos requisitos.

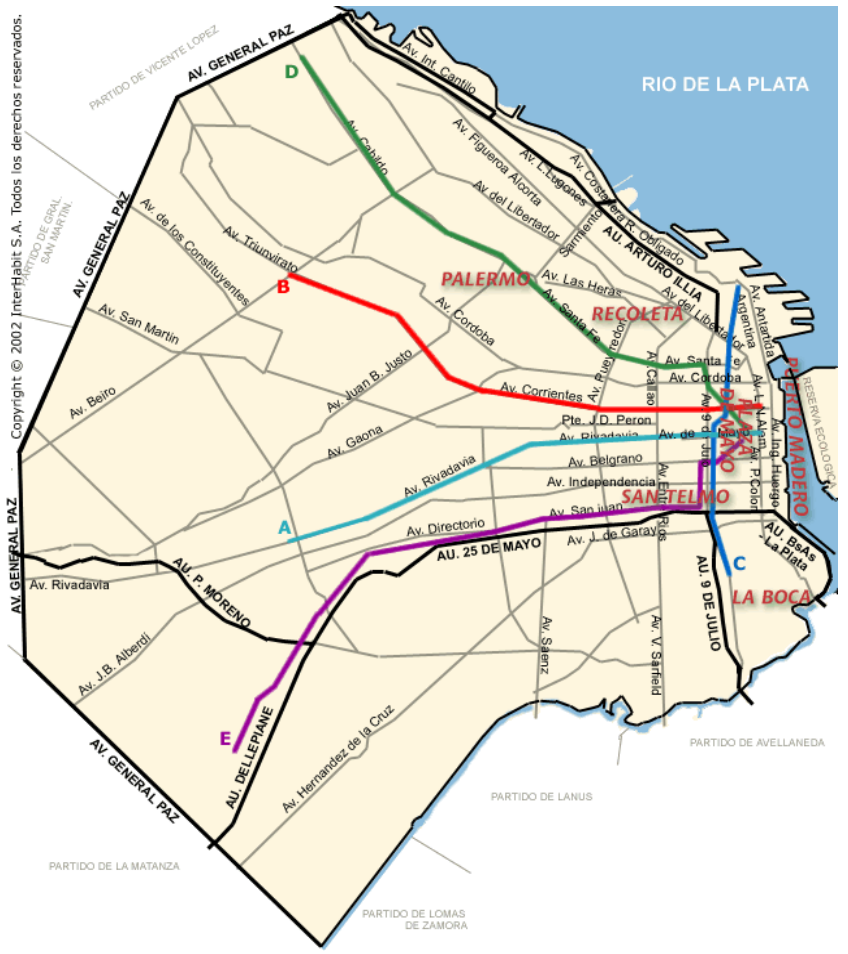

La Ciudad autónoma de Buenos Aires, CABA, (foto № 2) posee 2.891.151 habitantes, 1.329.681 varones, 1.560 .470 mujeres siendo el índice de masculinidad (cantidad de varones por cada 100 mujeres) 85,2 . Es la ciudad más densamente poblada, por kilómetro cuadrado. Dónde en el año 2001 vivían 13.679 habitantes por kilómetros cuadrado actualmente viven $\quad 14.185$ habitantes por kilómetro cuadrado ${ }^{4}$.

\footnotetext{
4 Fuente: Censo 2010, http://www.censo2010.indec.gov.ar/cuadrosDefinitivos. En cambio el censo del año 2001 arrojó los siguientes datos: La población fue 2.776.138 habitantes, la densidad se calculó en13.679 habitantes $/ \mathrm{km} 2$ tomando la superficie de 202,9 km2. Los datos definitivos del Censo 2010, dan un total de población de 40.117.096 de habitante todo el país. El total de hombres alcanza a 19.523.766 y el número de mujeres registrado 20.593 .330 .
} 
Fueron de origen distinto, las circunstancias por las cuales, los pobladores se establecieron en la ciudad. Algunos decidieron ser residentes por elección, otros arribaron a la ciudad buscando condiciones laborables y económicas más favorables a los que se les sumó los nativos del lugar. En la urbe conviven el llamado "progreso", la ilusión de una mejor calidad de vida, la posibilidad de una mayor expectativa laboral y económica con el estrés de la ciudad, los ruidos, la inseguridad, el individualismo, la contaminación ambiental, etc.

La ciudad autónoma de Buenos Aires está dividida actualmente por comunas. La Ley N²650/08 (publicada en B.0.2910, el 16/04/08) estableció la división de la Ciudad Autónoma de Buenos Aires en quince comunas. Saavedra comparte la № 12 junto a los barrios de Villa Pueyrredón, Villa Urquiza y Coghlan.

El barrio Saavedra lindera con los barrios de Coghlan, Núñez, y Villa Urquiza, y con el partido de Vicente López que se encuentra en la provincia de Buenos Aires. Sus límites son: Av. Gral. Paz (deslinde Capital - Provincia), vías del ex FF. CC. Mitre (ramal Suarez), Campana, Salvador María del Carril, La Pampa, Av. Dr. Rómulo Naón, Av. Monroe, Av. Dr. Ricardo Balbín, Franklin D. Roosevelt, Zapiola, Crisólogo Larralde, Av. Cabildo.

El nombre del barrio fue proporcionado por la Ordenanza Nº 26607 B.M 14228 del 4-5-1972. Según la ley 952 de la legislatura de la Cuidad Autónoma de Buenos Aires se instituye la fecha del 27 de abril como el "Día del barrio de Saavedra "en conmemoración al día de la fundación del mismo ${ }^{5}$.

Saavedra posee características particulares: es un barrio de grandes extensiones y de baja densidad demográfica (10.337 habitantes/ km2; censo 1998) comparados con los más céntricos. Está enclavado en una zona alta y por eso tiene unas bonitas lomas o barrancas entre la Avenida General Paz y el Parque Saavedra. Las calles con sus grandes arboledas que le dan un tranquilo aire provinciano.

Según De Certau, Girad, Mayol (1999) el barrio es un dominio del entorno social pues es para el usuario una porción conocida del espacio urbano en la que más o menos se sabe reconocido. Para Lefebre H., citado en Certau, Girad, Mayol (1999), el barrio es "...una puerta de entrada y salida entre los espacios calificados y el espacio

\footnotetext{
${ }^{5}$ Como curiosidad se destaca, a diferencias de los otros barrios de la CABA, que Saavedra es el único barrio de Buenos Aires que fue fundado formalmente con acta fundacional (se encuentra en el Museo Saavedra). Barriada, http://www.barriada.com.ar/saavedra.aspx
} 
cuantificado" (1999: 9). El barrio aparece como el dominio en el cual la relación espacio-tiempo es la más favorable para un usuario que allí se desplaza a pie a partir de su hábitat.

Existe, según De Certau, Girad, Mayol (1999), una diferencia entre el barrio y el hábitat. Cada uno de ellos tiene, con los límites que le son propios, un máximo aprovechamiento posible, ya que en uno y en otro son los únicos "lugares vacíos", dónde de una manera diferente se pueden hacer lo que uno quiere. El acto de aprovechar su interior incluye el de aprovechar las trayectorias del espacio urbano del barrio y estos dos actos son fundadores en la misma medida de la vida cotidiana en el medio urbano. El límite público - privado, que parece ser la estructura fundadora del barrio para la práctica del usuario, constituye una separación que une: no se puede entender en el contexto barrial el significado de uno sin el otro.

En el barrio Saavedra hay, a su vez, tres barrios bien diferenciados entre sí: el Barrio Presidente Mitre a espaldas de la fábrica Philips en Correa y Melián, que es una zona de construcciones precarias, el Barrio Presidente Roque Sáenz Peña que se extiende alrededor de la calle Valdenegro, con casas bajas y el barrio Cornelio Saavedra propiamente dicho, zona residencial con grandes casas con jardines, donde se distinguen las calles irregulares que le dan un tono sofisticado de privacidad, que se encuentra entre los Parques Sarmiento y Gral. Paz.

Los parques públicos de una ciudad son una opción interesante para aquellos sujetos que poseen deseos de realizar sus prácticas lúdicas. En cada barrio de la capital hay espacios verdes. La expresión espacios verdes o "verde urbano", según Ghilla Roditi citado por Cedeño Perez (2005), pertenece al lenguaje del siglo XX cuando la ciudad es reconocida como un organismo nuevo y complejo donde la coexistencia de una gran masa de humanos y de un gran número de actividades impone nuevas maneras de organización espacial y deja en evidencia nuevos modelos de comportamientos sociales.

La ciudad planifica "el verde urbano" como lugar destinado en forma específica a acoger y organizar la actividad del tiempo libre del ciudadano mediante alternativas de recreación, deporte y cultura. La OMS, Organización mundial de la salud, recomienda para las ciudades, una relación en referencia al espacio verde de 10 metros cuadrados a 15 metros cuadrados por habitantes. La ciudad de Buenos Aires se encuentra lejos de 
esta cantidad ya que existen sólo 2 metros cuadrados por habitante.

El barrio Saavedra, ubicado en la zona norte de la ciudad, es un barrio especial ya que posee tres grandes parques: el Parque Saavedra, escenario de la investigación, el Parque General Paz y el Parque Sarmiento. Cuenta además con varias plazas lo que posiciona a Saavedra, como uno de los barrios que más espacios verdes posee en la Ciudad de Buenos Aires.

Para considerar a los parques públicos urbanos, Cedeño Perez (2005) sostiene que se debe considerar, además del carácter, la superficie y la intención, aspectos como su localización geográfica, su diseño, sus usos y significados.

La autora cataloga a los parques públicos como espacios abiertos públicos polivalentes, de cierta extensión, ubicados en sectores de características geográficas específicas y en cuyo diseño la naturaleza, el paisaje y las áreas pavimentadas están en equilibrio, o deberían estarlo. La finalidad está orientada a facilitar la diversidad de usos, de tránsitos y sobre todo de interacciones sociales, lo que convierte a los parques en lugares de posibilidades donde se despliegan múltiples formas de vida de acontecimientos, a veces inusitados.

Las prácticas lúdicas en el barrio Saavedra, se ven favorecidas por la presencia de los parques y las plazas y por la gran cantidad de clubes de barrio que existen en la zona. La oferta de los mismos va dirigida esencialmente al público infantil, siendo el fútbol infantil la actividad que convoca mayor número de niños. Saavedra es representado futbolísticamente por el club Platense. A pesar de tener su cancha ubicada del otro lado de la Avenida General Paz, Vicente López, existe un arraigo muy importante de los habitantes del barrio con el equipo de Platense.

\section{El Parque Saavedra y sus prácticas lúdicas}

El Parque Saavedra tiene una superficie de $94.800 \mathrm{~km} 2$. Está rodeado por las calles: García del Río, Melián, Vilela , Besares , Conde , Pinto , Freire , Roque Pérez.(Foto № 3) 


\section{Dónde queda}

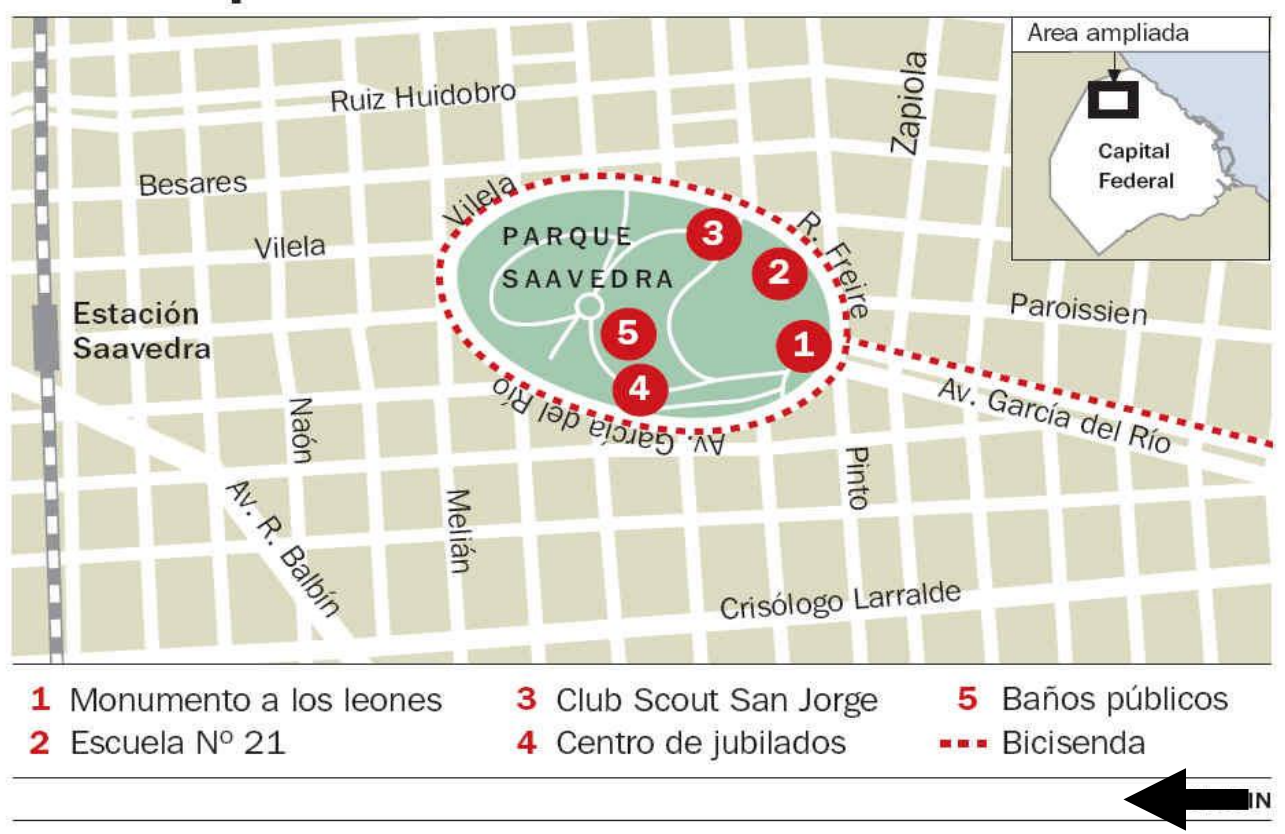

Foto № 3. Localización del Parque Saavedra

Posee como rasgo distintivo árboles añosos de distintas especies, pinos, palmeras y eucaliptos. A principios del siglo XX tenía un espléndido lago con góndolas y puentes levadizos, similar al que existía en Venecia. Actualmente posee una forma ovoidal con juegos infantiles y una extensa zona frecuentada por los aficionados al fútbol. Se puede observar también una parte de la antigua torre que, en tiempos remotos, bajaba su puente levadizo frente a la calle Pinto, cuando el parque era un bonito lago que el arroyo Medrano circundaba. Dos esculturas en mármol de Carrara pueblan el parque: una fuerte barca llamada "la caza del delfín" perteneciente a la familia Saavedra y un busto de Cornelio Saavedra.

Se inauguró el 27 de abril de 1873 con el nombre de "Paseo del lago ". Recolectaba las aguas del arroyo Medrano. Tenía también un torreón de entrada y un molino tipo holandés. Hacia 1890 se propuso construir un Hotel para Inmigrantes, canalizando el arroyo Medrano, así los buques podrían llegar por allí desde el Río de La Plata. Es el primer parque público construido en Buenos Aires, previo aún al parque Tres de Febrero (Palermo). Para los habitantes de Saavedra el parque posee una connotación histórica especial: allí se realizó la 1ํ fundación del barrio en 1873.

Cedeño Perez (2005) señala que los parques manifiestan, en efecto, una especulación utilitaria que va más allá de los elementos esbozados en su marco formal. 
Esto significa la existencia de usos transversales e inéditos, de múltiples maneras de apropiación espacial, de resignificaciones socio-espaciales. De ahí el carácter abierto y polisémico de un lugar que se convierte en muchos a la vez y cuya naturaleza se antoja compleja y llena de matices, como la misma realidad de la que hace parte.

Los parques se convierten a la vez en marco y acción, en ámbito de encuentros y pasajes, en un lugar inscripto, practicado pero también en escenario de múltiples miradas y percepciones. Allí se cristalizan momentáneamente una sociedad hecha de relaciones que se tejen sobre la marcha, de pactos y negociaciones a la hora de practicar los espacios que hablan de utilizaciones sostenidas en el tiempo por la costumbre, la cercanía, la necesidad.

En relación a los sujetos que acuden al Parque Saavedra observamos un interesante cruce de clases sociales como ser: los habitantes de casas tipo Chalet que rodean el predio y que van a pasear a sus perros, los vecinos de Belgrano que van a realizar prácticas de aerobismo (el parque es ideal porque tiene forma ovoide y está marcado el circuito a recorrer), los vecinos que viven circundando el parque, los sujetos que provienen de la provincia de Buenos Aires, los habitantes del barrio Mitre (barrio carenciado) y algunos "barra bravas" del Club Platense que realizan en forma recurrente partidos de fútbol.

Esta observación se articula con lo expuesto por Cedeño Pérez (2005) en relación a los parques públicos quien considera que los mismos son: metáfora de naturaleza y contemplación, intentos de un saneamiento ambiental e higiene pública por parte de los gobernantes, alternativas del mejoramiento urbano, espacios de interacciones y conflictos y aportan espacios para la recreación y socialización. Esta última característica surgió históricamente a partir de las nuevas condiciones industriales que agobiaban la vida de los habitantes de la ciudad. Se pensó, entonces, que era necesario producir espacios para que las masas de trabajadores pudieran tener una oportunidad de recrearse, descansar de las duras jornadas laborales lo que, en última instancia se traduciría en un rendimiento mayor en el ámbito laboral. Se dotaron los parques con elementos que no sólo propiciaban el descanso sino que favorecían el encuentro con los otros. Se construyeron además de caminos y bancos, zonas de juego, lugares para disfrutar del ocio y para estar con otros sujetos en un ambiente natural. Si bien en un comienzo se pensó esta dinámica para los trabajadores de las fábricas y su familia que 
no tenían otras maneras de disfrutar de su ocio, luego se extendió este formato para todos los habitantes.

Y por último otra particularidad que distingue al Parque Saavedra de otros grandes parques, son los pocos atributos materiales que hay en su interior. No posee ninguna cancha marcada o construida para realizar partidos de fútbol, partidos de básquet o partidos de voley. Sólo cuenta con una cancha de bochas y una de tejo en el club de jubilados. El parque presenta una extensa zona verde, que se convierte en un óptimo escenario para la realización de numerosas prácticas lúdicas.

\section{Jugando en el parque}

En la fase exploratoria de esta investigación se observó que existían en el parque numerosas prácticas lúdicas realizadas por distintos sujetos y que variaban en función de la edad y el género. Algunas se realizaban todas las semanas en el mismo horario y en general con los mismos jugadores. Otras se presentaban en forma espontánea sin presentar un patrón definido.

En el marco de las prácticas lúdicas con grupos que concurrían al parque en forma sistemática se registraron los juegos de: fútbol 9 vs 9 , fútbol de 20 vs. 20 , de voley 6 vs. 6 y 3 vs. 3, juegos de tejo y juegos de malabarismos. En relación a las prácticas lúdicas realizadas por los sujetos en forma no sistemática, se pudieron registrar: juegos de persecución, juegos de pelotas de niños y niños con adultos, juegos con elementos (raquetas, paletas, plato de plástico, etc...), juegos atípicos como hacer equilibrio sobre una bovina gigante de cable, lanzar zapatillas atadas por los cordones hacia un árbol, jugar a "la botellita"

Se observó también cómo en un mismo espacio, al lado de la plaza de juegos, se podían realizar entre niños de 10 y 12 años pases de voley, luego tiros al arco de fútbol y luego lanzamientos de un plato de plástico, ultimate (frisbee). Los jugadores en base a sus juegos pudieron re-crear el espacio según sus necesidades e intereses.

\footnotetext{
6 "La botellita" es un juego tradicional que se realiza con todos los participantes formando un círculo, intercalados por género: niño, niña, etc. Un jugador hace girar una botellita que se encuentra en el centro de la rueda. Cuando ésta deja de girar el niño señalado por la base de la misma debe darle un beso a la niña señalada por el pico de la botellita o viceversa. El tiempo de juego es establecido por los participantes
} 
Era interesante observar cómo en ciertas situaciones lúdicas se recreaba el espacio acomodándolo al sentido del juego. Por ejemplo, en "el palenque", (foto № 4) construido por un tronco de aproximadamente 8 metros de largo apoyado sobre dos troncos gruesos clavados en el césped, se pudo confeccionar el siguiente registro: un grupo de niños de aproximadamente 5-6 años se encontraban jugando a pasar de un extremo a otro del tronco desplazándose tipo "caballito". Luego se pudo observar a unos niños de aproximadamente 9-10 años realizando una mancha árbol, salvándose los jugadores de ser tocados al estar en contacto con el tronco. Más tarde se acercaron otros niños que disfrutaban saltando el árbol de un lado al otro y por último se pudo apreciar como dos adolescentes efectuaban un fútbol-tenis, utilizando "el palenque" como si fuera una red. Las situaciones descriptas pudieron dar cuenta como los jugadores recreaban su espacio de juego según sus necesidades e intereses.

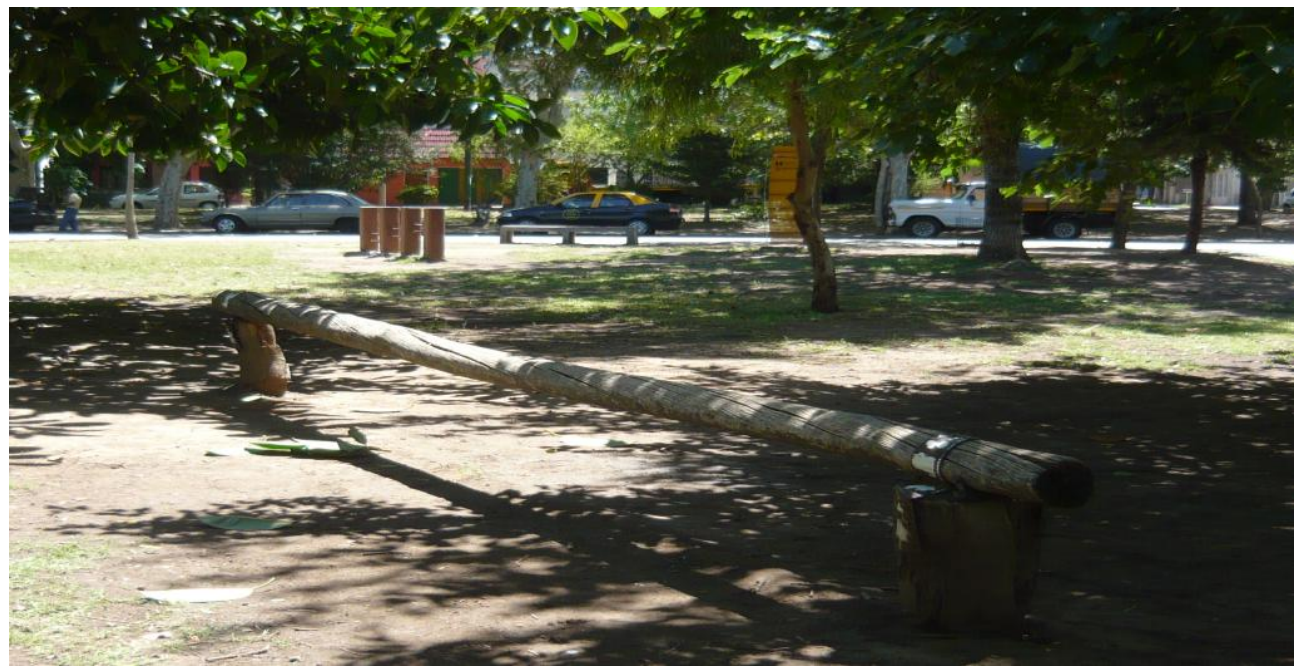

Foto № 4. "El palenque"

El aerobismo y la caminata eran dos actividades que poseían una gran convocatoria en el parque. Los días de semana entre las 18 hs y 20 hs era numerosa la cantidad de gente del barrio y de otros cercanos, que concurría para realizar su actividad atlética, atraídos por la forma ovoide y la existencia de una senda específica para transitar. Había varones y mujeres de todas las edades. Todos daban vuelta en el mismo sentido. Pero lo curioso era que la gran mayoría no ingresaba al parque, sino que sólo utilizaba la periferia. Los sujetos realizaban su actividad y una vez finalizada, se retiraban del predio. 


\section{Entre productores y consumidores espaciales}

En el estado del arte sobre los espacios públicos ya se había planteado la tensión existente entre los productores y los consumidores del espacio público. Delgado Ruiz (2002) colocaba el acento en las acciones realizadas por los usuarios en relación a los productores de lo urbano. De Certeau (1996) destacó las prácticas silenciosas de los sujetos, que reaccionan de diferentes maneras a lo planificado y organizado por los productores.

El autor francés da un ejemplo de la época de la conquista española en referencia a la situación planteada entre los colonizadores y los pueblos originarios. Los primeros no podían someter totalmente a los pueblos colonizados ya que ellos, de alguna manera, se las ingeniaban para continuar realizando sus ritos y mantener sus costumbres. No había combates, ni cambios, ni se rebelaban, sino que era una forma de no claudicar. Con los consumidores sucede algo parecido. Se apropiaron de consumos que ellos no crearon y respondieron con prácticas diferentes, con respuestas distintas a lo esperado por los productores.

El Parque Saavedra fue diseñado por un grupo de profesionales y políticos de la jurisdicción. Desde un enfoque espacial su construcción fue planeada para que los sujetos realicen determinadas prácticas. Pero en realidad: ¿los agentes sociales lo utilizaron según lo previsto por los diseñadores?, ¿aceptaron en forma pasiva lo que el espacio del parque les ofrecía?, ¿se puso en marcha, según De Certeau (1996), otras prácticas protagonizadas por los sujetos, que escaparon a la lógica de pensamiento de los constructores del espacio?

Los caminos de un parque desempeñan un papel orgánico: el de conectar y conducir a los usuarios a través de los distintos escenarios. Su trazado debe obedecer en principio a un objetivo claro y preciso: facilitar el tránsito de lo sujetos, permitiendo un desplazamiento cómodo atendiendo a las características del terreno. Algunas veces estos senderos claramente delineados no convocan a los sujetos y en cambio otros caminos alternativos si lo realizan. En el Parque Saavedra esto ocurrió en forma cotidiana. Se pudo observar que en general los sujetos seleccionaron sus caminos para desplazarse por el espacio verde. Algunos utilizaron las sendas asfálticas pero otros transeúntes crearon sus propias trayectorias. 
Calmels (2001) relata que un arquitecto se encontraba realizando el boceto de una plaza y omitió en forma deliberada la construcción de los senderos, es decir que la plaza quedó toda cubierta de césped. Una vez crecido éste, se dejo librado el paso de la gente por ella, y en el término de una semana el camino estaba hecho. Al caminar por la plaza, al cruzarla desde distintos ángulos, los caminantes dejaron un surco colectivo, una marca común. En ese surco se colocaron las baldosas que servirían de camino. ¿Pero qué fue lo que sucedió después? La gente no usó el camino de baldosas y cruzó la plaza por otros sectores originando nuevos senderos. Calmels (2001) señala que el espacio geométrico, el espacio vacío fue modificado espontáneamente, pero luego quién planificó y legalizó ese paso fue burlado. Agrega que la reacción ante los mandatos dominantes relacionados con el ordenamiento es la transgresión significada como "ir más allá" o "pasar a través de". Los caminantes de esa plaza fueron más allá de su propio camino, de su propio orden. Al desarrollo de la creatividad no le es ajena la necesidad de transgredir los diseños espaciales clásicos, necesidad de ir más allá de la norma. Y finaliza diciendo que el espacio vacío es una tentación para el deseo. De Certeau (1996) señaló que lo cotidiano se inventa con mil maneras de cazar furtivamente. Ambos autores exaltan la invitación del espacio a transgredirlo, con el significado de ir más allá.

El parque Saavedra es atravesado por una red de caminos de asfalto. En el año 2008 en un período de remodelación del predio, se construyeron nuevas sendas asfálticas. La intención de los productores era construir una nueva red vial que uniera toda la superficie del parque, pensada especialmente para los días de lluvia o días posteriores a la precipitación. Si bien se pudo observar que efectivamente los sujetos utilizaban estos caminos para no embarrarse existieron otros que se apropiaron de estos espacios asfálticos para realizar sus prácticas lúdicas.

Así por ejemplo se pudo registrar un niño de alrededor de 6 años desplazándose sobre su patineta, acostado y marcha atrás, por los senderos asfálticos. De idéntica manera se pudo observar 2 niños de aproximadamente 10-11 años jugando con dos paletas sobre el camino. En ambos casos los niños tomaron el espacio destinado a los transeúntes como un espacio propio de juego.

Las consecuencias de la remodelación del parque produjeron cambios en las prácticas de los sujetos. El nuevo camino asfaltado que se construyó dividió una amplia 
zona parquizada en dos sectores. Se habilitó para los transeúntes, paseantes, otras posibilidades de recorrer o cruzar el parque. Esta modificación generó un cambio de costumbres para los sujetos o grupos que ya se habían apropiado de un espacio determinado.

Así por ejemplo los agentes sociales que acudían a jugar al fútbol comúnmente en ese sector tuvieron que cambiar el espacio y extenderlo en otra dirección. El grupo de adolescentes que se reunía en el sector lindero a la escuela primaria, alejados de los caminos para tener una mayor intimidad, fueron sorprendidos con el diseño de la nueva senda. Como quedaban más expuestos tuvieron que cambiaron el espacio de reunión. En el punto más cercano de la senda que invadía "su" lugar pudieron dar cuenta de su protesta escribiendo sobre el cemento del asfalto la frase: "menos cemento y más verde“, como se puede observar en la foto № 5, abajo presentada. Es decir que las nuevas sendas invadieron zonas parquizadas, espacio de prácticas lúdicas, espacios de encuentro.

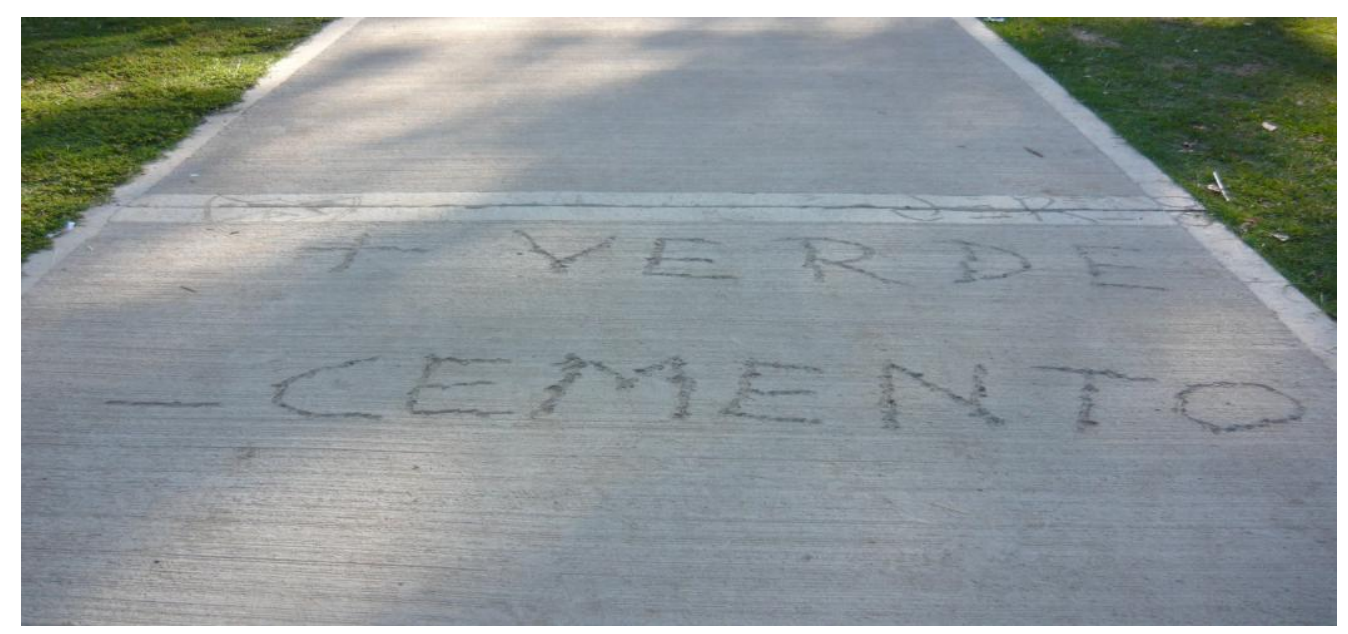

Foto № 5. "Más verde, menos cemento"

Otro ejemplo emblemático para considerar la relación entre el espacio construido por los productores y las acciones que ofrecen como respuestas los usuarios, se registró en un sector del Parque Saavedra que consta del "palenque" ya descripto en la página $\mathrm{n}$ ㅇ 21. La intención de los productores era que se utilice el tronco como un sitio para poder sentarse y descansar. Pero otra vez los consumidores de los espacios utilizaron "el palenque" para realizar sus prácticas lúdicas (fútbol tenis, mancha árbol, saltar el tronco). Se pudo comprobar que los usos fueron muy distintos, dependiendo 
de los intereses lúdicos de cada jugador. Muy posiblemente si los productores del diseño del parque agregaran otras construcciones los usuarios crearían diferentes formas de uso para lo cual fueron fabricadas. Los consumidores no son pasivos sino que dan distintas respuestas a lo propuesto. El espacio, concebido por los productores para determinar y condicionar ciertas conductas en los usuarios, en general no tuvo éxito. Los consumidores del espacio, desdeñando la intencionalidad de su construcción, lo utilizaron según sus propios intereses y allí recrearon sus juegos.

Continuando el análisis sobre los productores de los espacios y los usuarios de los parques Tonucci (2006) afirma que las plazas de juego para los niños, son un claro ejemplo de que los servicios que brinda la ciudad son pensados por los adultos para los adultos y no para los niños, aunque estos sean sus destinatarios declarados. ¿Por qué los sitios de juegos se encuentran en un terreno llano?, ¿se hicieron así para poder vigilarlos a todos juntos?, ¿nadie pensó que a los niños por ejemplo les gustaría un terreno con desniveles para poder esconderse? Las instalaciones de las plazas de juegos inducen a pensar que los adultos les indican a los niños qué juegos deben hacer en esos espacios. Son juegos repetitivos, banales, como hamacarse, deslizarse y dar vueltas, pensando que el niño es más parecido a un hámster que a un explorador, a un investigador y a un inventor. Son juguetes para juegos específicos, que deben ser usados tal como los adultos lo han pensado, pero los niños se cansan y comienzan a jugar con ellos de maneras menos aburridas, menos ortodoxas y entonces los juegos se vuelven peligrosos: saltan de la calesita en movimiento, bajan los toboganes cabeza abajo, trepan por el armazón de las hamacas, etc.

Considerando el concepto de territorio brindado por Delgado Ruiz (2002) y sumando el concepto de Bachelard (2012) sobre el espacio vacío y el espacio habitado cabe preguntarse: ¿cómo se llena ese espacio "vacío", en ese parque público, en el tiempo libre de los sujetos?, ¿cuáles son las prácticas lúdicas que efectúan los agentes sociales?

Para comenzar a develar estos interrogantes y de acuerdo a los registros realizados en el parque Saavedra, las prácticas lúdicas realizadas por los sujetos se pudieron agrupar para su primer análisis en: prácticas lúdicas realizadas por los sujetos en forma sistemática y práctica lúdicas efectuadas por los sujetos en forma no sistemática. En las 
primeras los agentes sociales repetían su situación de juego al menos una vez por semana, en cambio, los sujetos del segundo grupo no repetían su práctica de juego.

Es decir que en el espacio público del parque se pudo observar en el grupo que realizaba sus prácticas lúdicas en forma sistemática indicios del proceso de construcción de su territorio. En cambio los sujetos pertenecientes al grupo que realizaba sus prácticas lúdicas en forma no sistemática utilizaban el parque como un transeúnte, un morador ocasional, un jugador que usufructuaba el espacio público.

\section{La ciudad, lo urbano y el espacio público}

Delgado Ruiz (2002) señala que la antropología de lo urbano posee similitudes con la antropología del espacio. Abordan un objeto de conocimiento que puede ser considerado, con respecto de las prácticas sociales que alberga y que en su seno se despliegan como una presencia pasiva: decorado, telón de fondo, marco; pero también como un agente activo, ámbito de acción de dispositivos que las determina y las orienta, a la que los contenidos de la vida social se someten dócilmente.

El autor español diferencia la ciudad de lo urbano. Sostiene que lo urbano es un espacio que no puede ser morado. Afirma que la ciudad posee habitantes y que en cambio, lo urbano está constituido por usuarios. Señala que el ámbito de lo urbano por excelencia es el espacio público.

Según Delgado Ruiz (2002) el espacio público es un espacio diferenciado, pero las técnicas prácticas y simbólicas que lo organizan espacial o temporalmente, que lo nombran, que lo someten a oposiciones, yuxtaposiciones, complementariedades, que lo jerarquizan, etc., son poco menos que innumerables, son microscópicas, infinitesimales, y se renuevan a cada instante. No tienen tiempo para cristalizar, ni para ajustar configuración espacial alguna. Si el referente humano de esa antropología urbana fuera el habitante, el morador o el consumidor, sí que tendríamos motivos para plantearnos diferentes niveles de territorialización, como las relativas a los territorios fragmentarios, discontinuos, que fuerzan al sujeto a multiplicar sus identidades circunstanciales o contextuales: barrio, familia, comunidad religiosa, empresa, banda juvenil. Pero está claro que no es así. El usuario del espacio urbano es casi siempre un transeúnte, alguien que no está allí sino de paso. 
En los espacios públicos la territorialización viene dada sobre todo por las negociaciones que las personas establecen a propósito de cuál es su territorio y cuáles los límites de ese territorio. La idea en torno a la cual trabaja la proxemia ${ }^{7}$ es la territorialidad. En el contexto proxémico, la territorialidad remite a la identificación de los individuos con un área determinada que consideran propia, y que se entiende que ha de ser defendida de intrusiones, violaciones o contaminaciones.

En la misma dirección Leanza y Millán (2002) citados en Pavía (2005) esgrimen, desde una perspectiva geográfica, que la noción de territorio y territorialización se refieren al "conjunto de acciones que en nombre propio llevan a cabo individuos $u$ organizaciones, con la intención de ejercer control, influencia o dominio sobre un área geográfica determinada" (2005: 61). Pavía (2005) expone que en relación a los espacios de juego se orienta el territorio a una situación de defensa, relacionado con lo que Pichón Rivière (1985) denominó desde la psicología social, miedo al ataque y miedo a la pérdida ${ }^{8}$.

Los grupos que asistieron en forma sistemática al Parque Saavedra para realizar sus prácticas lúdicas compartieron un mismo espacio y un mismo tiempo por lo menos una vez por semana. Los agentes sociales se reunieron en un determinado espacio convocados por un juego, que ya había sido seleccionado a priori y fueron construyendo un proceso de territorialización. Si bien el parque es un espacio público no se registró ninguna situación donde el espacio de juego de un grupo estuviera ocupado por otro grupo. Es decir, que los agentes sociales se comportan como si hubiere un gran acuerdo general dónde ningún sujeto invade el espacio del otro. Bien distinto es lo que sucedió con los sujetos que asisten al parque en forma no

\footnotetext{
${ }^{7}$ A Edward Hall, se le atribuye el empleo de la palabra proxemia. Definió esta ciencia como "la ciencia que estudia las relaciones del hombre con el espacio que le rodea, en el que se comunica con hechos y señales" (1992: 25) en Hall E. (1992) La dimensión oculta. México, Siglo XXI Editores.

${ }^{8}$ Desde la Psicología Social Pichón Rivière considera que en toda situación nueva aparecen dos ansiedades básicas: el miedo a la pérdida de las estructuras existentes (ansiedad depresiva) y el miedo al ataque en la nueva situación (ansiedad paranoide), proviniendo esta última de nuevas estructuras en las que el sujeto se siente inseguro por carencia de instrumentación. Estas dos ansiedades coexistentes y cooperantes configuran la situación básica de resistencia al cambio. Pichón Rivière (1985) Estructura de una escuela destinada a la formación de psicólogos sociales en El proceso grupal. Buenos Aires Nueva Visión.
} 
sistemática para realizar sus prácticas lúdicas. Estos agentes sociales, transeúntes de los espacios verdes, no llegaron a conformar un territorio.

Delgado Ruiz (2002) analiza las diferencias entre el lugar y el espacio desde la óptica de M. De Certeau. El autor español señala que el esquema de la calle, la naturaleza puramente diagramática de lo que sucede en ella puede asimilarse a la noción de lugar, como la ha definido Michel de Certeau (1996), quien realiza una distinción conceptual entre lo que es el lugar y lo que es el espacio. Dice que:

Un lugar es el orden (cualquiera sea) según el cual los elementos se distribuyen en relaciones de coexistencia. Ahí pues se excluye la posibilidad para que dos cosas se encuentren en el mismo sitio. Ahí impera la ley de lo "propio": los elementos considerados están unos al lado de otros, cada uno situado en un sitio "propio" y distinto que cada uno define. Un lugar es pues una configuración instantánea de posiciones. Implica una indicación de estabilidad. (De Certeau, 1996: 129)

Al concepto de lugar De Certeau (1996) le opone el concepto de espacio y afirma: "...hay espacio en cuanto se toman en consideración los vectores de dirección, las cantidades de velocidad y la variable del tiempo. El espacio es un cruzamiento de movilidades" (1996: 129). Y luego agrega que a diferencia del lugar, carece pues de la univocidad y de la estabilidad de un sitio "propio". En suma el lugar es un espacio practicado. Delgado Ruiz (2002) considera que al lugar suele asignársele un nombre mediante el cual un punto en una mapa recibe desde fuera el mandato de significar. El espacio no tiene un nombre que excluya todos los demás nombres posibles: es un texto que alguien escribe, pero que nadie podrá leer jamás. Los habitantes del barrio Saavedra llamaban al parque "parque redondo", destacando su forma ovoide. A veces lo nombraban así para distinguirlo del parque General Paz. Algunos sujetos suelen confundir a éste llamándolo Parque Saavedra, solo por encontrarse en el barrio del mismo nombre.

Augé (2007) hace referencia a De Certau (1999) pero no opone el lugar al espacio. Auge (2007) acuñó el concepto de "no-lugar" para referirse a los lugares de transitoriedad que no tienen suficiente importancia para ser considerados como 
"lugares". Los lugares se caracterizan por ser históricos o vitales, espacios en los que nos relacionamos. Un "no-lugar" es una autopista, una habitación de hotel, un aeropuerto o un supermercado. Espacios sin historia, sin relaciones identitarias. Delgado Ruiz (2002) agrega que la calle, los pasillos del metro, las discotecas, las salas de espera, la gran superficie comercial son ejemplos de no-lugar.

Luego añade que la noción de no-lugar está emparentada con la de espacio. El lugar es configuración instantánea de posiciones. En cambio el espacio es extensión o distancia entre dos puntos, práctica de los lugares haciendo sociedad entre ellos, pero que no da como resultado un lugar, sino tan sólo, a lo sumo, una manera de pasar. Lo que se opone conceptualmente al no-lugar es la marca social del suelo, el dispositivo espacial que expresa la identidad del grupo, lo que el grupo debe defender contra las amenazas externas e internas.

Plantea Delgado Ruiz (2002) que el no-lugar es al lugar lo que el espacio al territorio. Es un punto de pasaje, un desplazamiento de líneas, algo que atraviesa los lugares y justo en el momento en que los atraviesa, por lo que, por definición, produce itinerarios en filigrana en todas direcciones, cuyos eventuales encuentros son precisamente el objeto mismo de la antropología urbana. El no-lugar es el espacio del viajero, es decir de su hablante, de todos aquellos que dicen el espacio y, haciéndolo, producen paisajes y cartografías móviles. En la ciudad el que decide sobre espacio es el transeúnte, el usuario de los transportes públicos o de las playas urbanas, el aficionado en el estadio, el consumidor extraviado en el centro comercial. Sobre todo es el espacio que la calle impone. Bachelard (2012) expresa que el espacio habitado trasciende el espacio geométrico. La vivencia del espacio es parte de la posesión, es parte del espacio amado. El espacio geométrico, el espacio "vacío" se va "Ilenando" con los hechos, vivencias y sensaciones que experimentan los sujetos.

El autor francés, a través del concepto de topofilia, señala una valoración humana de los espacios de posesión, de los espacios defendidos contra fuerzas adversas, de los espacios amados. Los espacios apropiados por los sujetos que realizaron sus prácticas lúdicas en forma sistemática representaban algo más que un espacio geométrico o un espacio vacío. La concurrencia semana a semana fue configurando un proceso de identidad a partir del concepto de territorialidad. Los sujetos establecieron un espacio 
considerado como propio, donde ejercían un dominio del mismo y que sería defendido contra fuerzas adversas si fuera necesario. 


\section{CAPÍTULO II}

\section{EL JUEGO DE LOS QUE JUEGAN}

Este capítulo analiza la relación existente entre la práctica lúdica elegida por los sujetos y el espacio donde se realizan. Encontramos dos vínculos diferentes. Por un lado, observamos que los actores que realizaban sus prácticas lúdicas en forma sistemática ya tenían sus espacio de juego seleccionado. Y que éste operaba como lugar de encuentro. La invitación y la convocatoria se realizaron para jugar un determinado juego que ya estaba elegido con anterioridad a la llegada al predio. Jugadores que realizaban en forma semanal su práctica lúdica, respetando el horario y el espacio que utilizaban frecuentemente. Por otro lado, se pudo observar que los agentes sociales que realizaron sus prácticas lúdicas en forma no sistemática, de acuerdo al espacio elegido, recreaban el mismo para efectuar su juego, es decir que los sujetos llegaron al parque sin haber seleccionado a priori a lo que iban a jugar.

Las prácticas lúdicas realizadas por los sujetos en forma sistemática desde una perspectiva del juego

Observamos seis grupos que concurrieron durante el tiempo de la investigación al parque Saavedra a realizar su práctica lúdica, por lo menos una vez por semana:

A. Grupo de voley de 6 vs. 6. (Sector 1 Mapa Lúdico, foto № 6)

En un sector del parque se reunían todos los domingos desde las 16 hs hasta las 20 hs un grupo de adolescentes, jóvenes y adultos mayores para jugar al voley. Generalmente conformaban equipos de 6 jugadores. Era un grupo mixto de 
aproximadamente 15 a 20 jugadores, con una presencia mayoritaria de varones. Varios integrantes concurrían todas las semanas.

La cancha se armaba unos quince minutos antes de empezar el juego. Un adulto mayor traía los elementos para su armado (la red, los hierros para sostenerla, las sogas para demarcarla y principalmente la pelota de vóley) y con la colaboración del resto de los jugadores armaban el campo de juego.

Los jugadores utilizaban vestimenta deportiva, aunque no usaban remeras de clubes o selecciones. Todos los participantes utilizaban zapatillas deportivas. Empezaban jugando tres jugadores contra otros tres y a medida que llegaban se sumaban más jugadores. Cuando cada equipo contaba con seis jugadores aumentaba la competencia y los equipos disputaban con intensidad los tantos. En cada equipo había un integrante que tomaba el rol de organizador, dando indicaciones sobre el juego que los demás aceptaban sin ningún inconveniente.

Los juegos alusivos al deporte que surgieron fueron desde las 16 hs hasta las 20 hs los siguientes: juego de 3 vs 3 y juego de 4 vs 4 con un pique previo, juego de 5 vs 5 y de 6 vs 6 . Las modificaciones se sucedían a partir de la llegada de nuevos jugadores. Con este último formato de juego aumentó la competencia.

Alrededor de la cancha había un público que seguía con interés el desarrollo del encuentro. En un clima tranquilo y ameno se alentaban y comentaban algunas jugadas pero sin discusiones ni situaciones de agresión.

Cuando ya no se podía jugar con luz natural finalizaba el partido. Se desarmaba la cancha y se saludaban entre ellos.

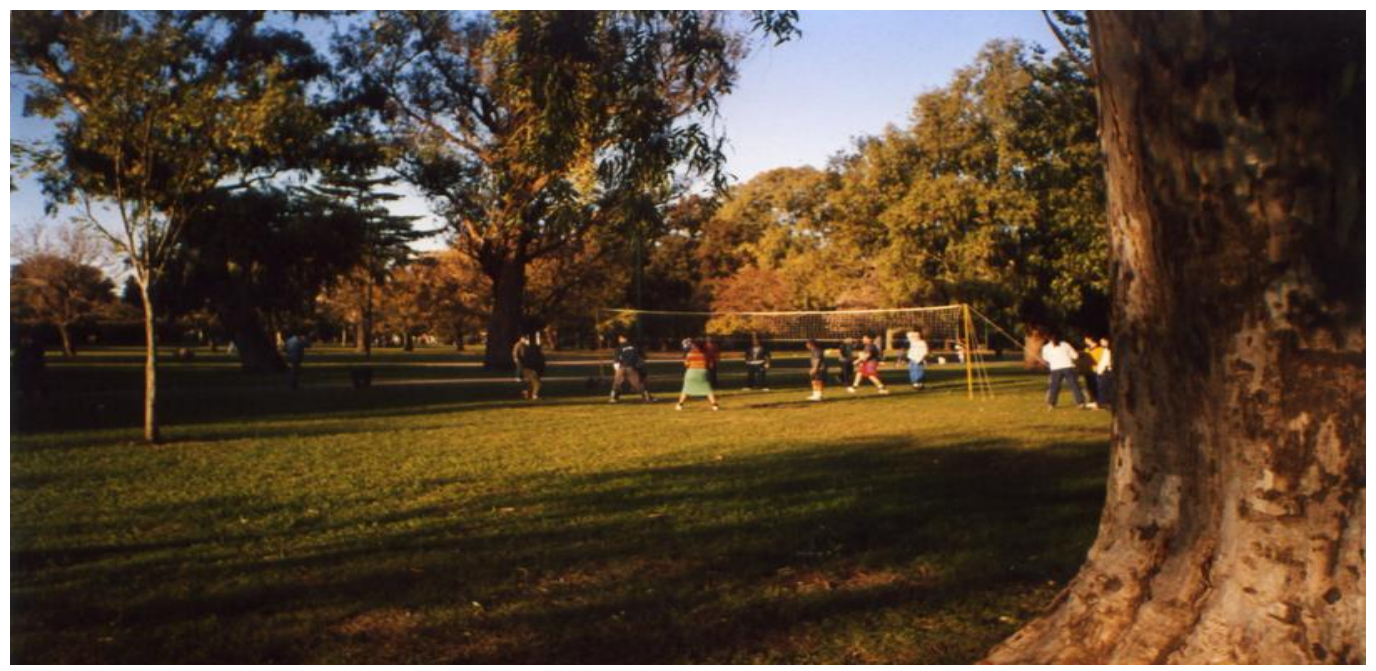

Foto № 6. Grupo de voley de 6 vs. 6 
B. Grupo de voley 3 vs 3. (Sector 2 Mapa Lúdico, foto № 7)

Este grupo de voley de 3 vs. 3 se reunía todos los domingos entre las 16.30 hs y las 20.30 hs durante el verano. Estaba conformado por 8-10 jóvenes varones entre 20 y 25 años, pertenecientes a la comunidad paraguaya.

La red estaba atada a un poste de luz por un extremo y por el otro a un árbol. Los límites estaban marcados con sogas. Jugaban con una pelota de color verde en un campo reducido, adecuando el espacio a la cantidad de jugadores.

Los jugadores se mostraron compenetrados con el partido y exhibían saberes técnicos. Aunque observamos reglas distintas en el juego a las que se realizan en forma tradicional, por ejemplo, la posibilidad en la recepción de llevar un poco la pelota con las dos manos abiertas.

A diferencia del otro grupo, aquí los sujetos practicaban el juego sin remera y en pantalones cortos. Tres jugadores realizaban la actividad lúdica sin calzado.

Las mujeres en este caso no jugaban, acompañaban al grupo sentadas en sillas, atendiendo a los niños y conversando entre ellas. Cuando caía el sol, las mujeres y los niños se retiraban dejando solos a los varones. Estos elegían este sector del parque para aprovechar la luz artificial. Seguían jugando un breve tiempo para luego sentarse a conversar y compartir unas cervezas.

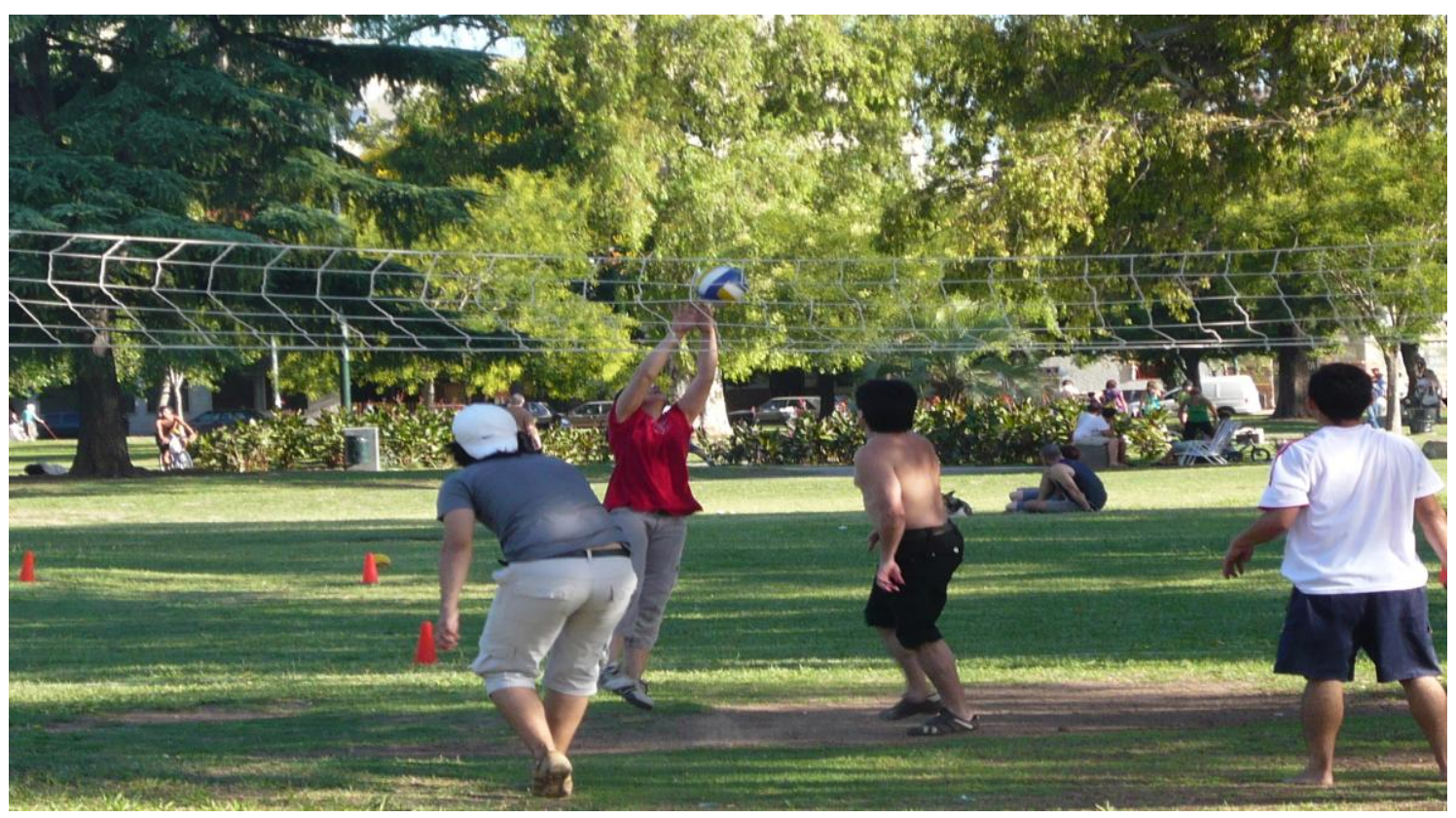

Foto № 7: Grupo de voley de 3 vs. 3 
Lo primero para destacar es que ambos grupos de voley se encontraban realizando su actividad a escasos 100 metros aproximadamente. En ningún momento hubo indicios de acercamiento o propuestas para realizar un partido en conjunto. Un grupo realizaba un juego de 3 vs 3 y el otro de 6 vs 6 , aunque eventualmente podía haber un partido con menos jugadores.

A pesar de pertenecer el juego a un mismo espectro deportivo y si bien las reglas en su mayoría eran similares existían algunas diferencias. Por ejemplo: los jóvenes de la comunidad paraguaya permitían llevar con las dos manos la pelota en la recepción. En relación al formato del juego el grupo que jugaba 6 vs. 6 podía realizar un juego de 3 vs. 3 tomando todo el campo de juego pero aceptando la posibilidad de un pique previo.

En cuanto al aspecto social las mujeres de la comunidad paraguaya no participaban del juego pero sí compartían la actividad como público. A determinada hora, cuando finalizaban los partidos, dejaban solos a los varones, y se retiraban del parque.

Pavía (2006) considera que la forma y el modo constituyen dos variables importantes para comenzar a comprender el juego. La forma está más vinculada a la actividad, en cambio el modo está relacionado con el sujeto. La forma se refiere la apariencia singular de un juego. Pavía (2006) hace una distinción entre la estructura profunda y la estructura externa de un juego. La primera está relacionada con el sentido propio del juego mientras que la segunda está ligada a las reglas básicas del mismo y se visualiza de manera más explícita que la primera.

En la estructura externa, a la que Pavía (2006) también denomina estructura de superficie de un juego, se suceden cambios relacionados con las negociaciones que entablan los jugadores, concernientes esencialmente a la temática de las reglas. La estructura profunda está referida al sentido del juego. Los jugadores acuerdan las modificaciones pero estos cambios tienen un límite en la estructura de superficie. No se traspasa el punto que origine un nuevo sentido del juego. En los juegos de voley se registraron diferentes cambios en la estructura de superficie. Así se pudo observar voley de 6 vs 6 , voley de 4 vs 4 y voley de 3 vs 3 . Se acordaban las reglas según la cantidad de jugadores. Pero el sentido de los juegos remitía al voley. 
Pavía (2006) considera al modo como la manera particular que adopta el jugador de ponerse en situación de juego, de acoplarse a la actividad propuesta. Implica una manera libremente elegida que expresa una perspectiva personal. Agrega que la libertad de elegir se ve influenciada por el contexto social e histórico.

El modo se emparenta en un punto con la actitud y con el deseo del sujeto lo que origina la fuerza incentivadora del juego. Esta combinación entre actitud y deseo por parte del sujeto y por otro lado la atmósfera particular del juego en lo referido a ser disparador de emociones (no sólo alegría, entusiasmo sino también puede incluir tristezas, decepciones, etc.) conforman la esencia del juego y lo diferencian de otras situaciones de la vida cotidiana. Se relaciona también con el hecho de que la disposición personal a jugar de un modo determinado incluye componentes cognitivos y afectivos, individuales y colectivos que posibilitan y condicionan el modo lúdico.

En los juegos registrados de voley llamó la atención las diferencias existentes en las dos prácticas lúdicas. Desde el concepto de forma se pudo observar cambios relativos a la estructura de superficie: se podía llevar la pelota con ambas manos y también arrastrarla en la devolución del saque. Sorprendió a los ojos del observador la particularidad que tres integrantes de uno de los grupos de 3 vs 3 jugarán descalzos en un terreno que tenía pasto pero no era precisamente suave.

Considerando el concepto de modo lúdico de Pavía (2006) se observó que esta singularidad provenía de una pauta y costumbre cultural de la comunidad paraguaya. El origen de esta característica formaba parte de las disposiciones, que son parte del sujeto y que están influenciadas por el contexto social e histórico. Y que son desplegadas en un entramado cultural distinto.

C. Grupo de fútbol "20 vs. 20” (Sector 3, Mapa Lúdico)

Este grupo estaba compuesto sólo por varones de diferentes edades. Se observó que habían: adolescentes, jóvenes y sujetos pertenecientes a la llamada "tercera edad". Se denominó de esta manera a este grupo de fútbol ya que, en general, los equipos contaban con numerosos jugadores superando la cantidad de 11 vs. 11 . 
Se encontraban en forma sistemática los días domingos a partir de las 11 hs y finalizaban su partido de fútbol alrededor de las 13.30 hs. El escenario elegido era siempre el mismo, salvo que haya llovido y se hubieran formado sectores con barro.

Una de las características de la indumentaria era que cada jugador se presentaba con la camiseta de su club preferido. Podían jugar los de Boca y River en un mismo equipo como los de Platense y Argentinos Juniors (clásicos rivales). La cantidad de jugadores podía ser desigual en cada uno de ellos. A medida que llegaban se iban sumando a los equipos. Nos pareció que no había una limitación al número de participantes. Esta observación fue confirmada en la entrevista con Silvio, uno de los organizadores, quién también nos contó cómo era la comunicación entre todos los jugadores. Nos dijo que en general todo estaba bien y que solamente había insultos con el equipo contrario si existía un roce fuerte. Con los compañeros del mismo equipo existían agresiones verbales cuando, un jugador no se desprendía de la pelota o finalizaba la jugada de un modo diferente a lo que pretendía uno de los líderes del grupo. En las diferentes observaciones no se registró ninguna escaramuza o golpes de puño. Los contenidos surgidos en la entrevista con Silvio, se utilizaron para recabar una mayor información acerca de los usos espaciales y prácticas de juego y no para abordar las representaciones de los sujetos.

Otro hecho saliente surgido de la entrevista con Silvio, fue el tema de la convocatoria. Él contó que la misma era abierta para los jugadores y podían incluirse en el partido, sujetos con problemas físicos, como por ejemplo "el Rengo" de 72 años. El grupo era heterogéneo: había flacos, gordos, altos, petisos, rápidos, lentos, hábiles y poco hábiles y jugadores con un buen estado físico y otros que solo caminaban la cancha. Todos ellos compartían ese mismo espacio de juego.

Los arcos eran artesanales realizados con caños. La cancha no tenía marcadas los límites laterales ni las líneas finales. Esta situación provocaba algunas discusiones entre los jugadores, ya que no se sabía si la pelota había traspasado las demarcaciones acordadas verbalmente. La conversión de los goles originaba gritos eufóricos, pero no se observaron actos provocativos hacía el otro equipo.

La mayoría de los sujetos repetían su concurrencia todos los domingos. Registramos que había distintas jerarquías entre los integrantes de los equipos. Distinguimos líderes definidos (Silvio era uno de ellos) que ordenaban y gritaban en la 
cancha y los demás le hacían caso. Había presentes hinchas de Platense y algunos integrantes de la barra brava del mismo club. En relación a las variables climáticas, aunque sean adversas (frío o mucho calor o llovizna), la mayoría de los jugadores asistían igual y el partido no se suspendía. La sensación era que este grupo "se apropió" de un sector del parque y que nadie se animaba a desplazarlo de ese espacio y menos a ocupar su lugar, sensación confirmada por Silvio en la entrevista. (Sector 3, Mapa Lúdico).

D. Grupo de fútbol 9 vs. 9 (Sector 4, Mapa Lúdico).

Este grupo concurría al parque todos los domingos entre las 17 hs y las 19 hs. Eran entre 20-25 adolescentes varones que jugaban en equipos con camisetas de fútbol que los identificaba. Pertenecían a la comunidad peruana. La cancha era artesanal: construían los arcos atando una soga entre dos árboles que hacía las veces de travesaño. Lo llamativo era que llevaban un balde de cal para delimitar el campo y las áreas. Había un sujeto que hacía de árbitro. Existieron indicios que los partidos pertenecían a un campeonato organizado. La vestimenta utilizada por los jugadores era específica para jugar al fútbol. Algunos utilizaban botines. Generalmente había un público observando los partidos conformado por mujeres adolescentes. (Sector 4, Mapa Lúdico).

Las prácticas lúdicas de fútbol descriptas anteriormente se abordaron desde Sarlé (2006). La autora introduce desde Wittgenstein (1988) el concepto de "parecidos de familia" ${ }^{9}$ para abordar el tema del juego y señala que las actividades que reciben el nombre de "juegos" entran en lo que denomina "family resenblance predicates" (parecidos de familia) y utiliza la metáfora de "cable formado por múltiples hilos". La superposición de muchas fibras, aunque ninguna recorra el cable en su totalidad, hace a la resistencia de la madeja. Considera que cada uno de estos hilos equivaldría a un juego pero ninguno de ellos recorre el cable en su totalidad. Wittgenstein (1988) citado en Sarlé (2006) argumenta que para llegar a una definición de juego el problema no radica en encontrar algo común entre juegos tan diversos como el ajedrez, las

\footnotetext{
${ }^{9}$ Wittgenstein utiliza este concepto en su libro Investigaciones Filosóficas (1988) para hacer referencia a los juegos lingüisticos.
} 
cartas, el juego de roles o el fútbol. El autor postula que estos fenómenos están emparentados entre sí y es a partir de este parentesco es que se le da a todos el nombre de juegos. Continúa diciendo Wittgenstein (1988) citado en Sarlé (2006), que para distinguir a los diferentes juegos, no se requiere llegar a analizar una propiedad o característica común que los identifique como parte de una clase, sino centrar la mirada en los juegos mismos y en lo que ocurre en ellos. En los "parecidos de familia" los parecidos surgen y desaparecen entre los diferentes juegos.

Las prácticas lúdicas de voley y de fútbol observadas en el Parque Saavedra presentaban algunos aspectos similares y otros que las diferenciaban. Los juegos orientados hacia el fútbol tenían una esencia común. Se utilizaba una pelota, había dos equipos, existían reglas (no todas fueron iguales) y el objetivo del juego era meter un gol en el arco contrario. Lo que consideramos distinto era lo particular de cada juego: no era lo mismo jugar al fútbol 20 vs 20 en un espacio muy amplio a jugar 9 vs 9 en una cancha marcada con las líneas laterales y finales.

Los juegos de voley se pudieron analizar desde una mirada similar. Lo común era utilizar una pelota, que haya dos equipos, y el objetivo del juego era marcar tantos tratando que la pelota pique en el campo contrario, le pegue a algún jugador y pique fuera de la cancha. O que el equipo atacante envíe la pelota fuera del terreno de juego o el lanzamiento hacia el otro campo que retenido en la red.

Lo distintivo en estas prácticas lúdicas, era la cantidad de jugadores que participaban del juego. No era lo mismo el juego de voley de 6 vs 6 , que el juego de 3 vs 3. Las reglas establecidas por los integrantes de los equipos eran diferentes. Entendemos que la forma de recibir la pelota, jugar sin calzado y sólo 3 vs 3 era costumbre de la comunidad paraguaya.

Analizamos estos juegos desde un enfoque cultural, a través del pensamiento de Huizinga (2007). Consideramos que el homo ludens, el hombre que juega, representa a su cultura, a las expresiones más primitivas de la civilización: el derecho, el saber, la guerra, la poesía, el arte, la filosofía. El autor holandés reduce todas ellas a una sola forma de juego: el juego competitivo. Es el ejemplo de los juegos de voley dónde se visualizaron las diferentes costumbres y tradiciones de los pueblos, en este caso el paraguayo y el argentino. 
Analizamos las prácticas lúdicas de voley y fútbol considerando una de las definiciones de juego de Huizinga (2007):

El juego es una acción u ocupación libre que se desarrolla dentro de unos límites temporales y espaciales determinados según reglas absolutamente obligatorias libremente aceptadas, acción que tiene un fin en sí misma y va acompañado de tensión y alegría y da la conciencia de ser "de otro modo" que en la vida corriente (2007: 45).

En los juegos de voley y de fútbol de 20 vs 20 la entrada y salida de los jugadores era libre. En el voley de 6 vs 6 el juego comenzaba desde un 3 vs 3 y a medida que ingresaban otros jugadores se iba adaptando el juego y modificándose las reglas. Según Pavía (2006) la forma del juego registraba cambios que no hacían perder la esencia del juego inicial. Tanto en este grupo como en el grupo del 3 vs 3 una vez comenzado el partido los nuevos participantes que llegaban debían esperar su turno para jugar. En el caso del fútbol de 20 vs 20 se registraron diferentes maneras de ingresar. A veces sucedió que si era un solo jugador entraba igual; otras veces había que esperar la llegada de otro compañero para realizar el conocido "uno para cada lado".

En referencia al espacio y tiempo las canchas estaban bien delimitadas y marcadas, con la excepción del fútbol de 20 vs 20 cuyos límites laterales eran indicados por la ubicación de los árboles en forma difusa. El tiempo de iniciación y finalización de estas prácticas lúdicas se mantuvieron en forma similar en las jornadas registradas. Las reglas en estos juegos ya estaban pautadas. Sólo en el grupo de voley de 6 vs 6 se modificaban las reglas según la cantidad de jugadores (si eran menos de 3 jugadores por equipos se aceptaba jugar con un pique previo).

La tensión estuvo presente en todas las prácticas lúdicas pero no de la misma manera. En el juego de fútbol de 9 vs 9 que pertenecía a un campeonato se observó que la tensión por ganar era mayor que en los otros juegos. En el fútbol de 20 vs 20 no se registró en forma tan intensa la importancia del resultado. Sí se gritaban los goles con mucho entusiasmo. La tensión estaba más focalizada en pasar bien la pelota y 
hacer una buena jugada ya que si esto no sucedía había un reto de los líderes del equipo. Estaba más relacionada con la jerarquía de los roles de los jugadores.

Los juegos de voley de 6 vs 6 y de 3 vs 3 y los juegos de fútbol de todos vs todos y de 9 vs 9 se pueden incluir en la categoría de juegos con predominio de la competición o juegos de agón propuesta por Caillois (1958). Éstos presentan un combate, una rivalidad al decir del autor, donde se crea artificialmente la igualdad de oportunidades lo que valida y valoriza el triunfo del vencedor.

En los juegos de voley y en el juego de fútbol de 20 vs 20 los equipos se armaron el mismo día del encuentro. A medida que arribaban los jugadores a la cancha, se iban distribuyendo en los equipos, siempre tratando que exista una igualdad numérica. En el caso del fútbol de 9 vs 9 los encuentros tenían un formato de campeonato, por lo cual los equipos ya estaban configurados a priori. Según Caillois (1958), el móvil de cada juego es para cada concurrente el deseo de ver reconocida su excelencia en un dominio dado. El agón supone: una atención sostenida, una preparación apropiada, esfuerzos y voluntad de vencer.

Pavía (2006) señala a la competencia como un modelo hegemónico de la búsqueda de la emoción. En esta situación existen límites a la negociación autónoma de la regla, acumulación de resultados y culto al ganador. Considerando a Elkonin (1980), este formato de juego se alejaría de una "situación arbitraria" y se convertiría en una situación arbitrada. Huizinga (2007) explicita que los juegos agonistas incluyen características relacionadas con la competencia. En cambio, Pavía (2006), dirige su pensamiento a una situación más arbitraria que incluye la riqueza de lo incierto.

E. Grupo que concurre a las canchas de tejo y bochas del centro de jubilados.

(Sector 5 Mapa Lúdico, foto № 8)

Una de las pocas construcciones que se registraron en el Parque Saavedra fue el centro de jubilados. Poseía una infraestructura que incluía: una cancha de bochas, 2 canchas de tejo de cemento con tierra con luz y una tercera cancha de tejo de arena que no se utilizaba con frecuencia. Las tres estaban marcadas con sogas. Además, contaban con un pequeño lugar cubierto, donde los sujetos jugaban a las cartas y al dominó y un sector de mesas que poseía una parrilla. Presentaba un cartel que 
indicaba a los paseantes la existencia de la "Unión Recreativa Parque Saavedra Jubilados. Bochas -Tejos" y del lado anverso dirigido a la calle García del Río decía: Escuela de tejo ${ }^{10}$.

Los sujetos que concurrían al Centro de Jubilados pertenecían mayoritariamente al sector etáreo de la llamada tercera edad. Los jugadores de tejo en general se reunían los días domingos y jueves de 18 hs a 21 hs en el verano y los sábados y domingos durante el invierno. La mayoría eran de género masculino. Las mujeres acompañan a los hombres pero no jugaban.

Los partidos se jugaban con mucha atención, concentración y entusiasmo. En general, miembros del centro de jubilados oficiaban como público y animaban a los jugadores. Se escuchaban voces de aliento y discusiones sobre la táctica más conveniente para utilizar en cada tiro. En un tablero se anotan los tantos para llevar el marcador.

En una oportunidad pudimos observar como una familia se acercó a los sujetos que estaban realizando un partido de tejo y preguntó si alguien les podía enseñar. La respuesta fue positiva y al finalizar el partido, uno de los jugadores, los llevó a una cancha y les enseño el juego, especialmente la manera de lanzar.

\footnotetext{
10 Se llama tejo a un juego que se puede practicar con un jugador y hasta 3 por bando. Es similar al juego de bochas y se disputa en una cancha rectangular de 12 metros por 2,5 metros. También es común que se practique en las playas de veraneo. Se juega con 6 discos de madera de distinto color por equipo y uno más pequeño denominado "bochín". Para iniciar el juego, suele realizarse un tiro de aproximación a la línea de fondo de la cancha: el bando que más "arrime" un tejo a dicha línea, sin salirse de la cancha, es el que comienza el juego lanzando el "bochín". Una vez arrojado el mismo, el juego consiste en lograr acercar la mayor cantidad de tejos este implemento. Cada bando debe lanzar hasta que uno de sus tejos, quede más cerca del "bochín" que el tejo más cercano del contrario, o que se acaben sus 6 tejos. Al finalizar los lanzamientos, se contabiliza un punto por cada tejo cercano al "bochín" del equipo ganador que supere al mejor tiro del equipo perdedor.
} 


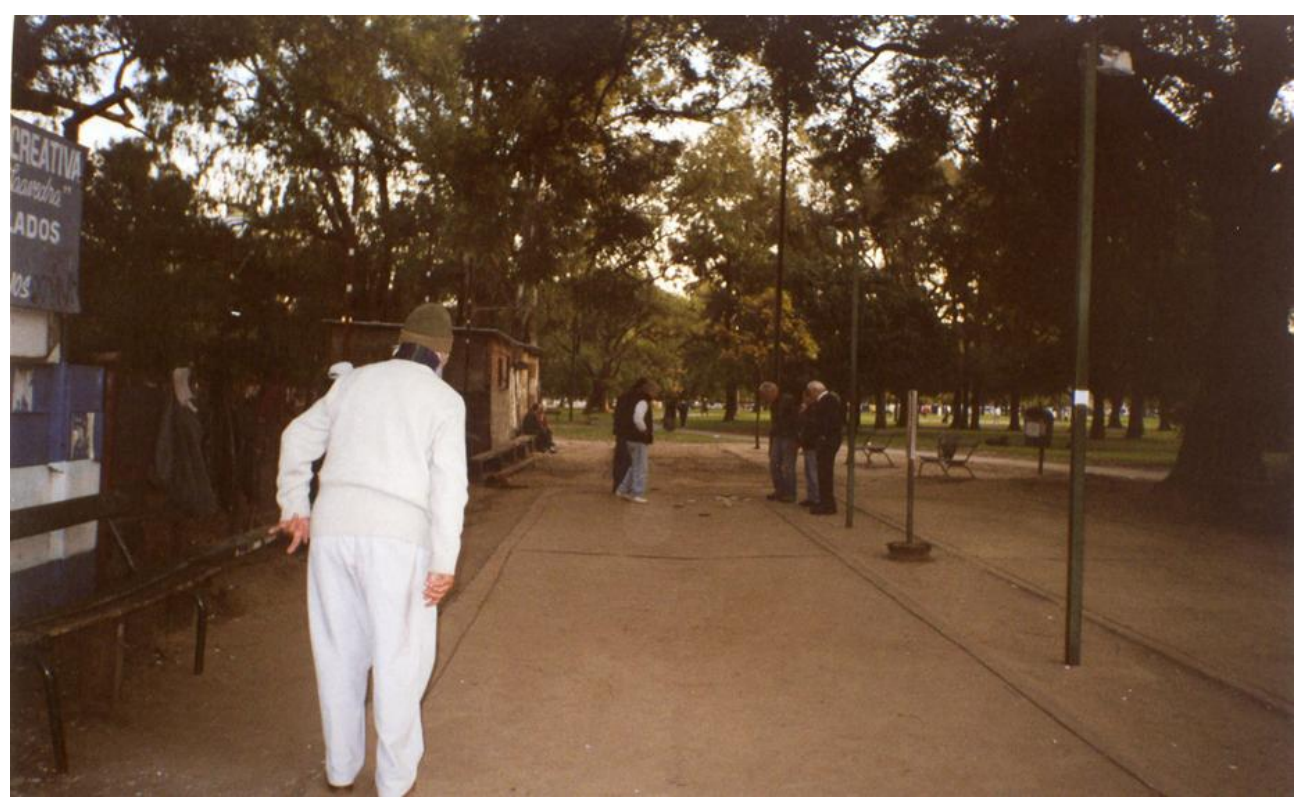

Foto № 8: El club de Tejo

Esta práctica lúdica nos llamó la atención por tres motivos. Primero, por realizarse en una institución inmersa en un parque público que contaba con personería jurídica e infraestructura propia. Segundo, por el cartel indicativo que presentaba el lugar haciendo mención a una escuela, por lo que se infiere que había sujetos que enseñaban y sujetos que aprendían. Tercero, nos resultó relevante la numerosa cantidad de sujetos que realizan esta actividad con gran entusiasmo.

Según Gerlero (2004), las actividades cercanas al ludus no son patrimonio exclusivo de un grupo de jugadores, se convierten en una práctica social. Las reglas, elementos esenciales de los juegos, son acordadas por los jugadores, se orientan hacia el polo del ludus configurándose un mayor control de los impulsos del juego a través de normas que provienen del contexto social. En algún momento estos juegos se comenzaron a repetir en su estructura y formaron parte del bagaje cultural de un grupo social. Es decir, que el tejo, emergió como una manera particular de relacionarse con los otros de un modo lúdico.

F. Grupo que toma clase de malabares (Sector 6, Mapa Lúdico).

Se reunían los martes entre las 18.30 hs y 19.30 hs. Había un profesor o coordinador que enseñaba habilidades con clavas y pelotas. El grupo incluía seis 
jóvenes entre 20 años y 30 años. Cuatro integrantes eran del género femenino y solo dos del masculino. La ropa era informal, con colores llamativos. (Sector 6, Mapa Lúdico).

Esta práctica lúdica surgió como un nuevo exponente de un sector de la juventud. Se pudo establecer una relación con el concepto de ludus de Caillois (1958), pero más vinculado con la posibilidad de realizar desafíos y poder cumplimentarlos. La práctica lúdica de malabares es parte de una nueva cultura de las actividades físicas.

\section{Las prácticas lúdicas realizadas por los sujetos en forma no sistemática desde una perspectiva del juego}

En las observaciones realizadas en el Parque Saavedra se distinguieron diferentes prácticas lúdicas efectuadas con objetos. Los jugadores, de género masculino y femenino, pertenecían a distintos sectores etéreos.

Con acciones extraídas del fútbol se registraron: varios partidos de niños, niños y jóvenes y niños y adultos en diferentes sectores del parque. Las canchas eran artesanales y los arcos se hacían con alguna vestimenta o utilizando elementos naturales. Observamos también juegos de patear al arco o de eludir a sus compañeros sin arcos marcados.

Se pudo ver a un niño y un adulto haciendo golpes de tenis con raquetas y otro grupo de dos niños jugando, unos con raquetas y otros con paletas de paddle. Se registró también a dos niños lanzando un plato de plástico, frisbee (plato de plástico que se lanza a un compañero).

Una situación particular se vivió en un sector del parque, donde existía un sitio para sentarse construido con un tronco, al que denominamos "el palenque" (foto № 4). Allí, como ya se explicitó en el capítulo I, se sucedieron diferentes prácticas lúdicas donde el espacio y los objetos tenían una resonancia distinta de acuerdo a los intereses y necesidades de los jugadores.

Agregamos a este registro, situaciones de juego que resultaron atípicas a los ojos del observador. Por ejemplo: dos adolescentes que aparecieron por los senderos del parque desplazándose en bobinas gigantes de cables (tipo TV por cable), haciendo equilibrio en ellas y luego jugando a ver quién se caía primero; un joven lanzando una 
pelota de hockey con el palo de hockey a su perro, que corría y la atrapaba; cuatro niños, entre seis y ocho años, que realizaban un juego de colgar unas zapatillas atadas por los cordones a un árbol (dos tiraban el calzado y los otros dos se encontraban arriba del árbol); y un grupo de niños y niñas entre once y trece años sentados sobre cartones alrededor de un pozo (de aproximadamente tres metros de diámetro) jugando a "la botellita".

Por último se observó una dinámica de juego a la que llamamos "fútbol familiar". Se pudo observar en reiteradas oportunidades, como mujeres y varones de una misma familia, luego de almorzar o tomar mate realizaban en forma conjunta un partido de fútbol con la participación de todos y todas. (Foto № 9).

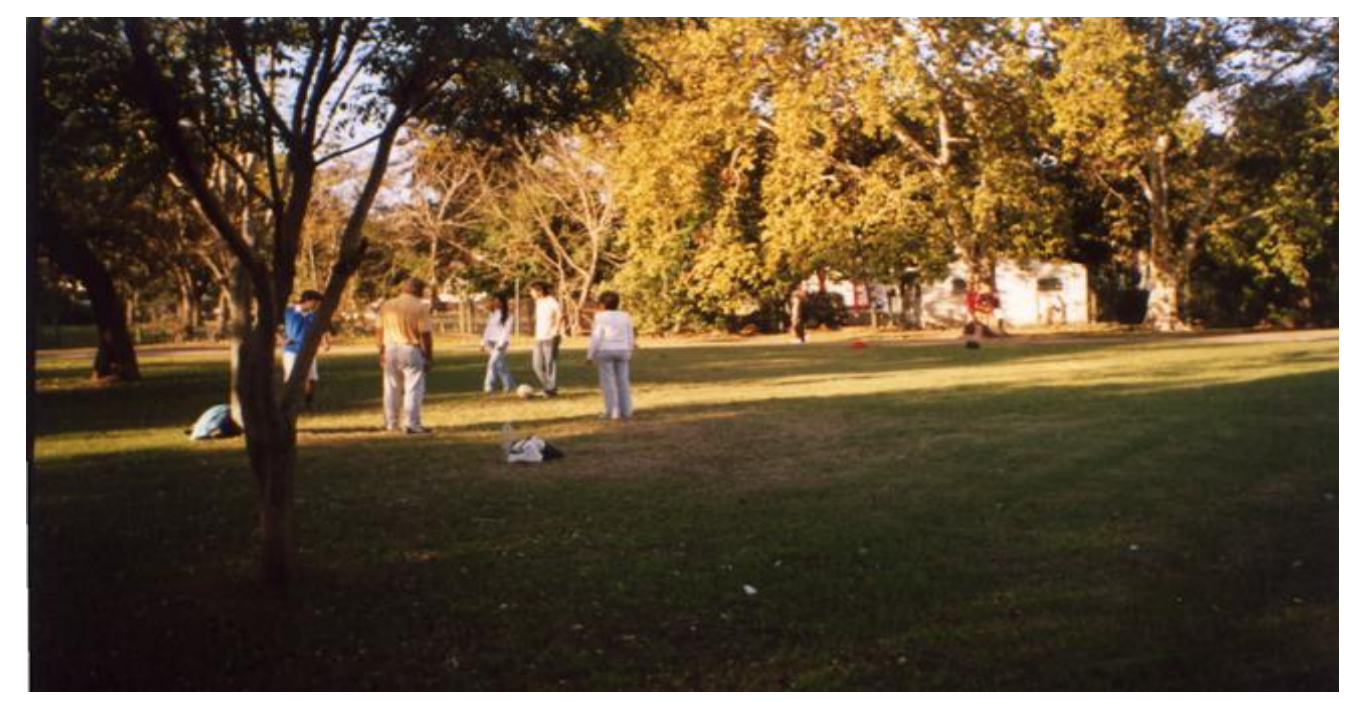

Foto № 9: "Fútbol familiar"

Los juegos registrados fueron muy distintos y muy variados. Se observaron juegos con elementos y juegos sin elementos, juegos extraídos de situaciones deportivas y juegos más tradicionales como la botellita.

En todas estas prácticas lúdicas registramos diferentes formas y modos de jugar según lo señalado por Pavía (2006). También observamos lo explicitado por Navarro Navarro Adelantado (2002) en referencia a la evolución y significado del juego y el jugar, binomio que mantiene dos rasgos fundamentales con el paso del tiempo: la acción de jugar y la diversión-recreación.

De acuerdo a la clasificación de Caillois (1958) en las prácticas lúdicas realizadas por los sujetos en forma no sistemática se registraron juegos en los que predominaba 
el vértigo, llinx. Se pudo observar así como los dos adolescentes que se trasladaban por los senderos sobre las bovinas gigantes y a un grupo de niños que sostenían una lona extendida e impulsaban a uno de ellos que estaba en el centro hacia arriba.

También se reconocieron prácticas lúdicas que estaban asociadas al ludus, más precisamente a la acepción del mismo, relativa al placer que está orientado en la experiencia de resolver una dificultad creada a propósito, arbitrariamente definida; el hecho de llevarla a cabo no reporta ninguna otra ventaja que la alegría íntima de haberla resuelta. Es el ejemplo de los niños que intentaban colgar en un árbol un par de zapatillas atadas por los cordones, el joven que lanzaba una pelota con un palo de hockey para que su perro la trajera en la boca o los niños que lanzaban el frisbee intentando que le llegue en forma cómoda a sus compañeros.

El juego de la botellita realizado en un grupo de niños y niñas entre 10 y 12 años recuerda lo explicitado por Gerlero J. (2004) acerca que las actividades cercanas al ludus no son patrimonio exclusivo de un grupo de jugadores, se convierten en una práctica social. Las reglas, elementos esenciales de los juegos son acordadas por los jugadores; se orientan hacia el polo del ludus configurándose un mayor control de los impulsos del juego a través de reglas que provienen del contexto social. En algún momento estos juegos se comienzan a repetir en su estructura y son parte del bagaje cultural de un grupo social.

En las prácticas lúdicas realizadas en forma no sistemática emerge con gran vigor la fuerza incentivadora del juego. Pavía (2006) señala, considerando el modo lúdico, que en el juego se puede observar la actitud y el deseo del sujeto asociados con su manera de jugar, resultante de un contexto social e histórico. A los ojos de un observador hay hechos que no se pueden comprender sin incluir la búsqueda de la gratificación de los jugadores. ¿Quién iba a suponer que dos adolescentes ingresen al parque trasladándose en una bobina gigante de cable de TV?, ¿cómo se explica que un joven lance con un palo de hockey, una pelota para que su perro la corra y se la devuelva, portándola en la boca?, ¿cómo comprender que un grupo de niños y niñas se encuentren en círculo esperando el destino de un beso a través de hacer girar una "botellita"? Los autores mencionados, Pavía (2006) y Gerlero (2004) coinciden en lo singular que resulta el juego para los sujetos y la búsqueda del placer inmersa en el mundo de las emociones. 
Pavía (2006) considera que el permiso y la confianza son dos aspectos importantes incluidos en el juego. La confianza hace referencia en que nada malo le va a suceder al jugador, ya que es una ilusión, considerando que estar inmerso en una apuesta irracional implica tener confianza en uno mismo y en el grupo de jugadores. El permiso se refiere a la posibilidad del sujeto de disfrutar el juego donde el jugador puede explorar y también equivocarse. Ambas condiciones permiten construir en el juego una atmósfera cálida y amena que facilite el surgimiento de las emociones, una de las principales características del juego. Un ejemplo observado es el juego de la "botellita", para realizarlo se necesita confianza en los compañeros y permitirse cada niño y niña a participar del mismo.

La confianza y el permiso permiten jugar el juego. Por el contrario la desconfianza o bajo umbral de permiso dificultan la relación del mismo. Se pueden relacionar estos términos con el concepto de resistencia al cambio, resistencia a lo nuevo de Pichón Rivière (1985). Incidiría en la participación del juego la plasticidad de cada sujeto para dar y darse la confianza y permiso para emocionarse. Por el contrario, otros sujetos, debido la poca plasticidad para desestructurarse y estructurarse evitarían la realización de juego y preferirían formatos más conocidos o esquemáticos o donde "la sorpresa no sorprenda" como un deporte con reglas fijas e institucionalizadas. Hay sujetos que esperan que se proponga el juego para aceptar la invitación a jugar.

Estas características explicitadas por Pavía (2006) y Pichón Rivière (1985) predominan en las prácticas lúdicas realizadas en forma no sistemática. Los sujetos se encuentran en el parque y necesitan de cierto grado de confianza y permiso para desplegar sus juegos. También las prácticas lúdicas observadas requieren un mayor grado de plasticidad por parte de los jugadores. 


\section{Eligiendo el juego}

Registramos en el Parque Saavedra, sujetos que concurrieron para realizar sus prácticas lúdicas con el juego seleccionado a priori y otros agentes sociales que arribaron al espacio verde sin haber seleccionado el juego a priori.

Para el primer grupo, la convocatoria e invitación se realizó para jugar un determinado juego que ya estaba elegido con anterioridad al arribo al predio. Los ejemplos registrados fueron: el grupo que realizó voley 6 vs. 6, los jugadores del voley 3 vs. 3, los sujetos que practicaban un fútbol de todos vs todos, los jóvenes del fútbol 9 vs. 9, los asistentes al club de tejo y los jóvenes que practicaban malabares.

En las prácticas lúdicas de estos grupos, registramos que los sujetos ya tenían pautados, formatos y reglas para una menor cantidad de jugadores. Así se pudieron registrar formatos de 2 vs. 2 con un pique previo, formato de 3 vs. 3 con cancha más chica, formato de 4 vs. 4,5 vs. 5 ídem al 6 vs. 6 . En general estas variantes del juego se utilizaban mientras los sujetos presentes esperaban que lleguen sus compañeros para completar el equipo y llegar a seis jugadores.

Todos estos grupos realizaban en forma semanal su práctica lúdica, respetando el horario y el espacio que utilizaban frecuentemente. Lo que se modificaba eran los participantes de las prácticas ya que no se repetían exactamente los mismos sujetos.

Las prácticas lúdicas realizadas por los sujetos que arribaron al parque con el juego seleccionado a priori, son parte de la cultura de los participantes y se posicionan como juegos de competición según Huizinga (2007) y juegos con predominio de la competición, agón, según la clasificación de Caillois (1958). Éstas prácticas se encuentran más asociadas al principio del ludus. Se registraron indicios emparentados con la dificultad gratuita que da lugar a numerosos juegos, a los cuales se les puede atribuir una virtud civilizadora que ilustran los valores morales e intelectuales de una cultura. Caillois (1958) enfatiza estos aspectos del ludus diferenciándolos de la paidia, potencia primaria de improvisación y alegría.

Se pudo establecer una relación con la forma y el modo propuesto por Pavía (2006) para la comprensión del juego desde la perspectiva del jugador. Es reconocible la forma de estas prácticas lúdicas ya sea voley, fútbol, tejo o los malabares. Lo que agrega una visión distinta es abordarlas desde el concepto del modo lúdico. Implica 
visualizar los sujetos a través de sus maneras de jugar, que conllevan indicios precisos del contexto social e histórico. Así se observó que, si bien la forma del juego de voley de 3 vs 3 era similar en dos grupos observados, lo que era distinto era el modo lúdico que adoptaba cada grupo. Se notaban hábitos y costumbres relacionadas con la experiencia y vivencia de cada jugador.

Por otra parte registramos las prácticas lúdicas que realizaron determinados agentes sociales que arribaron al parque sin haber seleccionado el juego a priori. Estos sujetos eligieron un espacio del parque para ubicarse, dejar sus pertenencias y luego desarrollaban sus juegos en el espacio circundante. El principio y el final de cada situación lúdica no estaban predeterminados. No seguía un patrón o formato definido establecido con anterioridad. Es el ejemplo de una familia con niños y niñas en edad escolar primaria que se ubicó cerca del sector de juegos de plaza. Allí, primero, seis niños extendieron una lona, colocaron a otro pequeño sobre la misma y jugaron a lanzarlo al aire. Luego tomaron un disco de plástico, frisbee y comenzaron a realizar pases entre ellos. Por último tomaron una pelota de fútbol y jugaron a sacarse la pelota entre todos.

Los participantes del fútbol familiar también arribaban al parque, elegían donde sentarse y dejar las pertenencias. Compartían un mate y en un determinado momento se realizaba este juego mixto. El inicio y el final eran inciertos. En todas estas prácticas lúdicas observamos de manera predominante la fuerza incentivadora del juego, es decir según Pavía (2006) la actitud de cada jugador sumada al deseo y asociada a una manera cultural de jugar.

\section{Sobre las diferencias entre los jugadores}

Hallamos diferentes características entre los jugadores que realizaban sus prácticas lúdicas. Para los sujetos que arribaban al Parque Saavedra con el juego ya elegido a priori existían variables que ya estaban predeterminadas. Conocían quienes eran los participantes, qué juego iban a realizar y qué espacio iban a utilizar. La incertidumbre del juego recaía en la vivencia lúdica de cada encuentro.

En cambio, para los sujetos que llegaban al predio sin haber seleccionado a priori su práctica lúdica, las variables no estaban presupuestas. La elección del juego se 
realizaba en el parque al igual que el espacio que se iba a utilizar. La incertidumbre incluía también si el juego iba a salir, es decir, si la propuesta lúdica se podía concretar. La entrada y la salida de los jugadores eran libres, como registramos en el ejemplo de la familia que acudió al parque con varios niños, que fueron modificando los juegos y los jugadores, ya explicitado en "Eligiendo el juego", en la página anterior.

En este tipo de prácticas se evidenció en forma más profunda el juego como una acción gratuita y deliberada. Estas particularidades se pudieron abordar desde el concepto de Huizinga (2007) referidas a que el juego es una acción u ocupación libre, que posee un rasgo de incertidumbre y que posee un fin en sí mismo.

Otra diferencia entre los jugadores la abordamos desde el concepto de resistencia al cambio de Pichón Rivière (1985). Los sujetos que llegaron al parque sin haber elegido el juego a priori, necesitaron de una mayor plasticidad para apropiarse de lo nuevo, para construir su práctica lúdica. En cambio los sujetos que ya poseían seleccionado el juego no tienen que "poner tan en juego" su plasticidad ya que los participantes y el juego ya son conocidos.

Otra distinción que observamos radica, según Caillois (1958) ,que en las prácticas lúdicas de los sujetos que concurrieron al parque con el juego ya elegido (con excepción del grupo que hace malabares), existió una predominancia de los juegos de agón, asociados a una acepción del ludus que remitía ya a pautas culturales y aceptadas por la sociedad.

En cambio en las prácticas lúdicas de los sujetos que arribaron al parque sin haber elegido el juego a priori registramos una predominancia de juegos relacionados al vértigo, Ilinx (por ejemplo los adolescentes que se trasladaban en las bobinas gigantes o los niños que jugaban a lanzar a otro colocado en una lona). También se visualizaron prácticas lúdicas orientadas al ludus, dónde los jugadores se plantearon un desafío previo, encontrando la gratificación en la superación del mismo. Como por ejemplo el grupo de niños que jugaban a colgar las zapatillas atadas en un árbol.

También analizamos desde la clasificación de los juegos de Caillois (1958) que en ambos tipos de prácticas el espacio extenso, amplio y parquizado del Parque Saavedra facilita la concreción de los juegos, ya sea los de competición o los de vértigo.

A modo de cierre señalamos que, de acuerdo a la frecuencia de las prácticas lúdicas realizadas por los sujetos y en referencia al momento de elección del juego se pudo 
concluir en este capítulo que las prácticas lúdicas que realizaban los sujetos sistemáticamente, es decir aquellas que tenían por lo menos una repetición semana a semana, coincidían con las prácticas lúdicas efectuadas por los sujetos que ya habían elegido a priori su juego.

Del mismo modo se pudo considerar que, coinciden generalmente las prácticas lúdicas ejecutadas por los sujetos en forma no sistemática, o sea, que no se registró una reiteración de la misma en una unidad de tiempo semanal, con las prácticas realizadas por los sujetos que arriban al parque sin haber elegido su juego a priori.

En el próximo capítulo se indagó en cómo seleccionan el espacio los sujetos para realizar sus prácticas lúdicas y su relación con las prácticas lúdicas realizadas por los sujetos en forma sistemática y las prácticas lúdicas efectuadas por los jugadores en forma no sistemática. 


\section{CAPÍTULO III}

\section{EL ESPACIO DE LOS QUE JUEGAN}

\section{ACERCA DEL ESPACIO}

La etimología de la palabra espacio, según Calmels (2001), significa campo de carreras o cualquier lugar extenso apto para caminar se refiere a una capacidad que posee el cuerpo, la de trasladarse en carrera. De esta manera se deja de lado la tendencia de considerar al espacio como algo estático y se profundiza su significado hacia una acepción relacionada con el movimiento .Desde la psicología analítica, Calmels (2001) señala que el término espacio posee desde el lenguaje una relación con el movimiento, con el cuerpo y la motricidad. Se puede considerar también el espacio del sujeto mismo demarcado por coordenadas espacio-temporales: arriba-abajo, derecha-izquierda, adelante-atrás; de la misma manera se puede hacer referencia al volumen y a la capacidad que tiene el cuerpo de hacer sus límites naturales, una frontera de intercambio con los demás cuerpos, al considerar el adentro-afuera.

Calmels sostiene que "El espacio de juego es un territorio configurado que excede el campo de juego. Incluye no solo el espacio que encierran las márgenes, sino también los lugares de frontera, espacios circundantes al campo de juego" (2001: 81). El autor explicita que el campo de juego es, en cambio, un espacio acordado y en muchos casos preparados para el hacer lúdico. Configura el lugar esencial del espacio de juego. Además agrega que el margen diferencia espacios y hace que estos no se confundan. En cambio el límite hace que los espacios no sean infinitos, es un fin que divide y que separa. Por ejemplo, una línea lateral de una cancha de voley hace la función de margen. El margen permite fronteras, articula espacios y a quienes habitan u ocupan los mismos. Las demarcaciones de una cancha, ya sea fútbol o voley, abren un espacio para el espectador. Trasponer el margen del campo de juego suspende provisoriamente las acciones del jugador, por el contrario, trasponer los límites del espacio de juego "excluye" al jugador del juego. Es importante analizar que, 
mantenerse al margen, transforma al jugador en espectador lo que le permite continuar una relación con el juego.

Las prácticas lúdicas presentadas en esta investigación se basaron en dos componentes esenciales: el juego y el espacio. Es muy frecuente en el universo lúdico la predisposición a investigar la temática del juego más que la temática del espacio. Hay numerosos trabajos académicos centrados en el primero, pero muy pocos estudios en relación a una mirada espacial. El enfoque de esta investigación se focalizó no solo en el juego y sino también en el espacio.

El pensamiento de Parlebas resultó importante para jerarquizar la relación entre el juego y el espacio. El autor francés señaló que "el espacio material representa el soporte irrecusable de todo juego" (1988: 119). Definir un juego es en parte, establecer las características de los lugares donde se realiza: dimensiones y normas, naturaleza y consistencia (materiales artificiales, elementos de plena naturaleza). Esta articulación insoslayable posibilitó investigar los indicios de selección de los espacios en las prácticas lúdicas realizadas por los sujetos.

Los aportes de Pavía (2005) fueron también importantes para esta investigación. El autor proporcionó conceptos precisos acerca de lo que es un sitio y un lugar, tratando de diferenciarlos del lenguaje cotidiano, donde muchas veces se los utiliza como sinónimos. En el plano de los espacios socio recreativos, si bien son términos similares, adquieren sentidos ligeramente distintos. El sitio alude a la condición de espacio perfectamente ubicable y situado, independientemente que alguien lo use. El lugar connota la relación vincular de un sujeto particular con un sitio que resulta, por lo menos para él, también muy particular. Es decir: es el sujeto el que convierte un sitio determinado en su lugar mediante la ocupación y el uso sostenido y sistemático.

Es pertinente preguntarse: ¿qué característica de un lugar influyen en la elección del mismo por parte de los jugadores, descartando otras opciones posibles. Interrogarse, por ejemplo: ¿por qué el grupo de niños y niñas que jugaban a "la botellita" seleccionaron ese sitio del parque y no otro, al igual que los niños que lanzaban las zapatillas a un árbol elegido, desechando otras opciones?

Considerando el sitio y el lugar, en tanto espacios restringidos, concretos y tangibles reportan un escenario. Se hace referencia a un espacio determinado, pero considerando de una manera muy particular sus atributos materiales y simbólicos, los 
cuales le imprimen un carácter específico. Pavía (2005) pone como ejemplo la caracterización diferente de un polideportivo a un parque de diversiones y de una sala de jardín a una sala de velatorios; un escenario es el sitio más los atributos materiales y simbólicos. Pensar en términos de escenario lleva a pensar las características singulares de un sitio y su impronta social, cultural y política.

En referencia a los espacios socio recreativos, en este caso un parque público como el Parque Saavedra, los atributos incorporados al sitio hicieron que se vea diferente a otro parque público, a otra plaza y a otro espacio verde. Además una de las características de este parque es su amplia superficie parquizada sin atributos materiales lo que permite que gran cantidad de sujetos puedan realizar prácticas lúdicas sin interferirse los unos con los otros. Favorece, además, que los sujetos puedan tener opciones de re-crear los espacios parquizados en función de los juegos elegidos.

\section{El espacio seleccionado}

Parlebas (1988) proporcionó tres categorías para definir y analizar el espacio en relación a la práctica lúdica: A) La dimensión del espacio domesticado-salvaje, B) El espacio psicomotor y C) El espacio sociomotor. Para esta investigación se consideró solamente la categoría A.

La dicotomía domesticado -salvaje refiere a una escala que tiene en cuenta el grado de codificación y de estabilización que el hombre hace sufrir al medio, con vistas a instituir y realizar sus prácticas ludodeportivas. Parlebas (1988) caracteriza al polo "domesticado" como un medio estable, previsible y estandarizado. Es el caso de los estadios, de los gimnasios, de las piscinas, que han sido total y artificialmente construidos. Este espacio, normalizado y predefinido, tan rigurosamente domesticado no ofrece ninguna información útil al atleta, al gimnasta o al nadador, favoreciendo la eficacia de los estereotipos motores. Por el contrario, consideró que en el polo "salvaje" el medio es incierto, inestable no acondicionado. En este caso los usuarios requerirían en forma constante información para la toma de decisiones. Es el ejemplo del espacio de la naturaleza, que da lugar a excursiones y expediciones vividas por sus adeptos como una aventura extraordinaria: exploración submarina, vela de altura, 
descensos rápidos en canoa, kayak, vuelo a vela, etc. En todas estas prácticas ludodeportivas los sujetos debieron incorporar los datos cambiantes del entorno físico en las decisiones motrices.

Entre el polo domesticado y el polo salvaje surgió, según el autor francés, el medio semi-domesticado. Éste se caracteriza por que el medio está parcialmente acondicionado, ni totalmente estabilizado, ni totalmente salvaje. Parlebas (1988) consideró que existen diferentes grados de domesticación. La información originada en un espacio semi-domesticado era importante para el practicante ya que tiene que tomar decisiones sobre la marcha.

Según estas categorías el Parque Saavedra, en relación a las prácticas lúdicas, es un espacio domesticado. Aunque en algunas situaciones particulares podemos definirlo como un medio semi-domesticado, teniendo en cuenta la variable climática (lluvia, viento, etc.) y la variable arquitectónica (construcción parcial o total de atributos materiales).

\section{Las prácticas lúdicas realizadas por los sujetos en forma sistemática desde una perspectiva espacial}

En el capítulo anterior se analizaron las características de las prácticas lúdicas efectuadas por los sujetos desde un enfoque sobre el juego; en cambio en este capítulo se abordaron las prácticas lúdicas desde una perspectiva espacial. Consideramos esencialmente: los espacios seleccionados por los sujetos, la forma de construcción de los espacios de juego, los campos de juego y el público asistente.

A. Grupo de voley de 6 vs. 6. (Sector 1 Mapa Lúdico, foto № 6)

El sector elegido para instalar la cancha de voley fue una zona de pasto rodeada de árboles en la cual no había ramas que obstaculizarán el espacio aéreo. Según los registros realizados la localización de la cancha se repitió en las sucesivas observaciones. El armado artesanal de la misma tenía un proceso particular. Uno de los jugadores, un adulto mayor es el que se encargó de traer todos los elementos 
necesarios para su construcción. Llegaba quince minutos antes del comienzo de la actividad y junto con otros compañeros procedían a su armado. El equipamiento constaba de una red, dos hierros para sostenerla, sogas para marcar la cancha (líneas laterales y líneas finales) y este jugador llevaba la pelota.

Según los conceptos esgrimidos por Pavía (2005) se pudo visualizar que hubo una apropiación de este sitio como lugar. Los sujetos con su ocupación y el uso sostenido de su práctica lúdica convirtieron, día a día, este sitio determinado en un lugar de esparcimiento. Este proceso favoreció el entramado vincular de los jugadores, transformándose en uno de los pilares principales del encuentro de los participantes.

Desde la mirada de Calmels (2001) se consideró que el espacio de juego estaba conformado por la cancha de voley y el espacio circundante. Se tuvo en cuenta como campo de juego, espacio acordado para el hacer lúdico, sólo la cancha de voley. Esta apreciación permitió también incluir al público que miraba los partidos de voley como sujetos integrantes de la práctica lúdica. Más allá que algunos de ellos, los que estaban esperando su turno para ingresar, se convirtieron luego en jugadores.

Cerca de las 20 hs, ya sin luz natural finalizaban los partidos. El adulto mayor que había armado la cancha dirigía el desarmado junto a los compañeros. El equipamiento y la pelota de voley se la llevaba él. Con un saludo entre todos terminaba la jornada.

B. Grupo de voley 3 vs 3. (Sector 2 Mapa Lúdico, foto № 7)

El espacio elegido fue un sector del parque que tenía pasto. La característica principal era que poseía un poste luz y un árbol alineados, de tal manera, que se pudo atar la red de voley de un extremo al otro. La proximidad al poste de luz artificial le permitió al grupo jugar después de la caída del sol y por otro lado, una vez terminada la práctica lúdica, poder reunirse a charlar, comer y beber, primero con la familia que oficiaba de público y luego solamente los varones.

Los registros realizados se relacionan con el concepto de patrones de acontecimientos de Alexander (1981) citado en Pavía (2005), que proviene del campo de la arquitectura urbana. Este autor argumenta que ciertas características del espacio general que remiten imágenes vinculadas con lo viviente, cómodo, exacto y libre, cuando actúan en armonía constituyen los patrones de acontecimientos. Esta cualidad 
comprende la armonía que se establece entre lo material y lo simbólico de cada escenario con lo que el observador espera que allí acontezca.

El patrón no solo se refiere a los acontecimientos humanos sino también a aspectos de la naturaleza clima, sol, viento etc. Existe además una tensión entre la idea de patrón (fijo, inflexible, inmutable) y la de acontecimiento (eventual y extraordinario). Lo que es inseparable es el espacio material y las acciones que allí se suceden, que están atravesadas por las representaciones sociales, históricas y culturales de los sujetos.

Según nuestras observaciones, con recurrencia los jugadores de voley de 3 vs. 3 definían el lugar del encuentro, el horario de la convocatoria y la posibilidad de compartir después del juego, un momento con su familia y luego sólo con los compañeros varones. Lo eventual, según los registros efectuados, resultaron: los compañeros presentes en el juego, la formación de los equipos, la cantidad de equipos y la llegada de otros sujetos, solamente para el encuentro social después del juego.

La reiteración de la elección del espacio refiere a que los sujetos encontraron una armonía entre los atributos materiales, la cancha de voley y los atributos simbólicos, la posibilidad de encontrarse con otros compatriotas paraguayos.

Los sucesos observados se relacionaron con la integración de las ideas de los patrones y los acontecimientos que refieren a representaciones sociales, históricas y culturales de los sujetos.

C. Grupo de fútbol “20 vs 20” (Sector 3, Mapa Lúdico).

El escenario elegido era siempre el mismo: un amplio sitio del parque sin árboles alejados de los senderos, salvo que haya llovido y se hayan formado sectores con barro. Los arcos eran armados por dos sujetos que arriban un rato antes del partido. Los construyeron con caños en forma artesanal, incluido el travesaño y lo aseguraban con sogas que clavaban en el pasto. Lo que no incluyeron en la cancha fue la demarcatoria de los laterales, lo que provocaba algunas discusiones entre los jugadores.

La práctica lúdica de este grupo se pudo relacionar fuertemente con el concepto de territorio. De acuerdo a Delgado Ruiz (2002) la territorialidad remite a la 
identificación de los individuos con un área determinada que consideran propia, y que se entiende que ha de ser defendida de intrusiones, violaciones o contaminaciones. Según los registros realizados hubo fuertes indicios de apropiación del espacio. La cancha de fútbol artesanal se construía todos los domingos en el mismo sector siendo el lugar del encuentro y convocatoria.

Por otra parte, la inclusión entre los jugadores de personajes emblemáticos del barrio, sumado a algunos integrantes de la "barra brava" del club Platense hacía impensable suponer que otros sujetos pudieran quitarles este espacio totalmente apropiado. El partido en general no se suspendía. Se jugaba a pesar de las inclemencias climáticas llovizna, mucho calor o mucho frío. Sólo se modificaba la localización parcial de la cancha cuando los sujetos notaban la presencia de sectores con barro.

D. Grupo de fútbol 9 vs 9 (Sector 4, Mapa Lúdico).

El espacio elegido resultaba extenso. El criterio de selección espacial se basaba en la posibilidad de armar los arcos de fútbol. Estos se realizaron en forma artesanal atando una soga entre dos árboles que cumplía la función de travesaño. Lo llamativo de este grupo, a diferencia del grupo de "20 vs. 20", es que llevaron baldes de cal para marcar los laterales y las líneas finales.

Abordamos la elección realizada por los sujetos sobre el espacio socio recreativo desde el concepto de amenidad señalado por Atkinson y Robinson citados en Pavía (2005). En respuesta al interrogante planteado de cuáles son los atributos materiales y simbólicos que marcan, caracterizan un espacio como recreativo, los autores confeccionaron una guía de preguntas para evaluar la calidad del medio ambiente físico que incluye cuatro interrogantes básicos: ¿asegura la supervivencia?, ¿evita la enfermedad?, ¿contribuye a promover el rendimiento humano eficaz o poco usual? y ¿fomenta la comodidad, el placer o el deleite? Considerando esta última pregunta, Atkinson y Robinson citados en Pavía (2005), se interesan por los tipos de respuestas que el hombre da a aquellas circunstancias del medio ambiente que generan sentimientos o sensaciones de agrado, comodidad, o deleite y postulan una "una escala de amenidad". El concepto de amenidad revisado puede aportar datos interesantes para definir un espacio socio recreativo. La amenidad se puede considerar 
un carácter que sintetiza la cualidad de divertido y entretenido, la de atractivo y placentero, que distrae y deleita (por vivo, cómodo, exacto) y que genera deseos de preservación, defensa y promoción.

Los integrantes de la comunidad peruana repetían la elección del lugar. De las cualidades del concepto de amenidad, se puede señalar en este caso que las mismas están más orientadas a los deseos de preservación y defensa del lugar que solamente a la cualidad de placentero y divertido. Se relaciona más con la idea de territorio y el sostenimiento de una identidad cultural. La reiteración del escenario elegido resalta los atributos simbólicos de este grupo emparentados con su historia y cultura. Generalmente hay un público observando los partidos conformado por mujeres adolescentes.

E. Grupo que concurre a las canchas de tejo y bochas del centro de jubilados.

(Sector 5 Mapa Lúdico, foto № 8)

La actividad convocante en el Centro de jubilados era el juego de tejo y en menor medida el juego de bochas. El escenario presentó una armonía entre los atributos materiales y los atributos simbólicos. La infraestructura que exhibía la institución fue construida en forma paulatina y su máximo logro fue el haber conseguido la personería jurídica, ofreciendo a la comunidad barrial un espacio recreativo donde, además de poder jugar al tejo y a las bochas, podían encontrarse con otros sujetos para realizar una asado y jugar a las cartas (el Centro cuenta con una pequeña construcción con techo y una parrilla). La adquisición de luz artificial contribuyó para que los sujetos, especialmente de la tercera edad, se pudieran reunir también por la noche.

Las prácticas lúdicas del Centro de jubilados, se abordaron para su análisis, con otras miradas no tradicionales en el campo de las actividades físicas en relación al espacio y sus modos de uso. Desde el campo de la geografía, Williams (1995) citado en Pavía (2005) sostiene que una experiencia recreativa se estructura sobre el soporte de tres componentes básicos: la actividad, el contexto social y el escenario entendido como contexto físico. En la práctica, los espacios recreativos ofrecen a los sujetos diferentes escenarios con variados atributos materiales y simbólicos. Para que la experiencia recreativa opere con toda intensidad, el conjunto de estos atributos debe 
estar dotado de una cualidad singular percibida como tal por el sujeto. Un espacio ya sea domesticado o salvaje considerando el pensamiento de Parlebas (1988), deviene en escenario recreador cuando al ser percibido como un todo por el sujeto posee una cualidad de conjunto que trasciende a cada uno de sus atributos y que guarda armonía con la actividad recreativa que se pretende desplegar en él.

Pavía (2005) consideró que un escenario, es el sitio más sus atributos materiales y simbólicos, incluyendo su impronta social, histórica, cultural y política. El club de tejo presentó para los sujetos que allí concurrían un significado singular y una apropiación particular de este sitio. La dimensión del término escuela de tejo conlleva la acción de enseñar y aprender y la predisposición de compartir los conocimientos de este juego con otros sujetos que no tuvieran experiencia y que sólo deseaban conocerlo. En la práctica, los espacios recreativos ofrecían a los sujetos, diferentes escenarios con variados atributos materiales y simbólicos.

F. Grupo que toma clase de malabares (Sector 6, Mapa Lúdico).

Este grupo de jóvenes con su coordinador eligieron para realizar su actividad un espacio particular. Un sector de pasto rodeado de árboles, lejos de las sendas peatonales. Alrededor de uno de ellos dejaban los elementos, clavas y pelotitas, y las pertenencias personales.

Analizamos la selección de este espacio recreativo con el concepto de carácter de un lugar. Williams (1995) y Alexander (1981) citados en Pavía (2005) realizaron aportes interesantes que permitieron definir propiedades acerca de los espacios recreativos. El primero, geógrafo, rescata de un espacio como principal característica la capacidad de exaltar o relajar. El segundo, arquitecto urbanista, valora los patrones de acontecimientos (humanos y no sólo humanos) que crean el carácter de un lugar. Éste se podría definir, entonces, como una característica, peculiaridad, naturaleza o condición de una persona o hecho, una marca que lo distingue y diferencia.

El grupo de malabares encontró su lugar en el sector descripto. La suma de características propias originó que los jóvenes eligieran ese espacio y no otro para realizar su práctica lúdica. 


\section{El espacio de juego}

En referencia a los grupos observados se consideró según Calmels (2001) que el espacio de juego del grupo que realizaba voley de 6 vs. 6 incluía también el espacio circundante, es decir que comprendía también al público. Éste estaba formado por los jugadores que esperaban su turno para ingresar al campo de juego y los acompañantes, familiares o sujetos ocasionales que miraban el partido. En el caso del voley 3 vs. 3 el público estaba formado principalmente por mujeres y niños pequeños que observaban el partido.

En el juego de fútbol de 20 vs. 20, las márgenes del campo de juego eran difusas. Las líneas laterales y finales de la cancha no estaban marcadas por lo tanto se esperaba un acuerdo entre los jugadores contarios para ver si la pelota se había traspasado las márgenes. Existían pocas personas en el rol de público, en general acompañantes de los jugadores. No había mujeres. En el fútbol de 9 vs. 9 el campo de juego, las líneas laterales y líneas finales estaban marcados con cal. El espacio de juego incluía al público formado por jóvenes de ambos sexos y los que observaban el partido en forma ocasional. En el club de tejo se considera a las dos canchas de tejo como el campo de juego. En el espacio circundante había pocos sujetos que miraban el partido. La minoría eran mujeres. En relación a la práctica lúdica de malabares los márgenes del espacio eran difusos. La actividad estaba centrada alrededor de un árbol donde los sujetos dejaban sus pertenencias. Allí también estaba el material a utilizar: clavas y aros. En general no había público. Los jóvenes estaban concentrados en su tarea. En este caso no era necesario demarcar el campo de juego.

Retomando lo señalado por Parlebas (1988) que el espacio material representa el soporte esencial de toda práctica lúdica y deportiva, se pudo observar que los practicantes del fútbol y del voley, en cualquiera de sus modalidades, llegaban con anticipación al espacio de juego y armaban sus canchas.

Los sujetos que jugaban al voley traían la red, sogas, estacas para construir las canchas. El grupo de la comunidad paraguaya portaba también una escalera para anudar la red a la altura requerida por el juego. Los jugadores del fútbol llevaban los caños plásticos, sogas y estacas para armar los arcos. Los sujetos del fútbol 9 vs 9 traían también cal para pintar las líneas demarcatorias de la cancha. En el caso del club 
de tejo las canchas ya estaban construidas. Los primeros sujetos que llegaban ponían en condiciones el lugar limpiando el interior de las canchas de tierra. La práctica de los malabares se realizaba en el mismo espacio semanalmente. Este acondicionamiento espacial en referencia a las prácticas lúdicas se realizaba en forma rutinaria antes de cada encuentro.

Estos espacios domesticados, soportes de las prácticas lúdicas, se convirtieron en espacios semi-domesticados ante los avatares climáticos y las refacciones arquitectónicas realizadas en el Parque Saavedra. En referencia al voley los sujetos armaron la cancha en un espacio próximo; los jugadores del fútbol corrían los arcos hacia los sectores de pasto que se encontraban en mejor estado. Se registró que de todas maneras sectores de barro formaban parte del terreno de juego y los sujetos debían incluir esta información cuando el juego se desarrollaba en ese espacio. En el caso del voley se pudo registrar que los días ventosos los jugadores debían adecuar la información, desvío de la trayectoria de la pelota, para realizar su juego en forma eficaz, especialmente en el saque.

El espacio seleccionado para realizar el juego se repitió según las observaciones realizadas. Esto se relaciona con el concepto de Pavía (2005) cuando considera que un lugar conlleva una situación afectiva para ser elegido. Bachelard (2012) considera que el espacio habitado trasciende al espacio geométrico. La cancha es algo más que un rectángulo marcado sobre el pasto: significa la presencia del cuerpo y el movimiento e incluye los vínculos, las miradas, las actitudes, etc.

\section{Las prácticas lúdicas realizadas por los sujetos en forma no sistemática desde una perspectiva espacial}

Los espacios de las prácticas lúdicas que realizaban los sujetos en formas no sistemáticas, responden según Parlebas (1988) a la categoría de espacio domesticado. El mismo estaba estabilizado, invariante y no necesitaban los jugadores información del medio para efectuar su juego.

Lo que sí hay que señalar, según los registros realizados, es que un mismo espacio se utilizó como soporte de diferentes juegos. Es el caso de los niños y adolescentes que se encontraban en el sector del "palenque". Los objetos tenían diferentes 
significados según los juegos realizados. El espacio y los objetos tenían una resonancia distinta de acuerdo a los intereses y necesidades de los jugadores. En conclusión los intereses de los sujetos fueron variando rápidamente. No sólo se elegía el juego sino también con quién jugarlo.

Consideramos, según el pensamiento de Calmels (2001), que el espacio de juego coincidía con el campo de juego. Es decir que no se habían establecido los márgenes ni límites del espacio utilizado. Un niño podía recorrer el espacio para escaparse de la mancha sin considerar ningún límite. En cambio, en relación al "fútbol-tenis" los adolescentes habían marcado la cancha y limitado el campo de juego.

Pavía (2005) considera que el lugar connota la relación vincular de los sujetos con el sitio y que es el sujeto el que convierte un sitio determinado en su lugar mediante la ocupación y el uso sostenido y sistemático. En relación a las prácticas lúdicas efectuadas en forma no sistemática, según los las observaciones, los sujetos según su juego elegían el espacio para realizarlo. No hubo un uso sostenido del mismo, por lo cual, en estas prácticas, no se puede hablar de lugar.

En referencia a los atributos materiales del parque fue llamativo como un tronco "tipo palenque" que se construyó en su origen para que los sujetos se puedan sentar y descansar se convirtió en un objeto que facilitó la creatividad de los jugadores para realizar distintos juegos. Considerando el sitio y el lugar, en tanto espacios restringidos, concretos y tangibles reportan un escenario. Se hace referencia a un sector determinado, pero considerando de una manera muy particular sus atributos materiales y simbólicos, los cuales le imprimen un carácter específico.

Los juegos de manchas de persecución, juegos de paleta o raqueta, patear al arco con una pelota de fútbol, frisbee, fútbol familiar no favorecieron la apropiación del espacio ya que el desarrollo de la práctica lúdica era ocasional. Siguiendo este pensamiento se registró que los sujetos seleccionaron sus espacios de acuerdo a los sectores no ocupados y que no hubo inconvenientes en modificar el espacio de juego si otros sujetos se instalaban en la proximidad.

Por último se observó una dinámica nueva para la familia que es el "fútbol familiar" (foto no 9). Observamos, en reiteradas oportunidades, como las familias formadas por mujeres y varones luego de almorzar o tomar mate, realizaban en forma conjunta un partido de fútbol con la participación de todos. Esta práctica lúdica se pudo interpretar 
desde Atkinson y Robinson citados en Pavía (2005) a través del significado de lo que los autores definen como amenidad. Este concepto revisado puede aportar datos interesantes para definir un espacio socio recreativo. La amenidad se puede considerar un carácter que sintetiza la cualidad de divertido y entretenido, la de atractivo y placentero, que distrae y deleita (por vivo, cómodo, exacto) y que genera deseos de preservación, defensa y promoción. Las familias elegían el espacio para merendar, tomar algo y luego en ese mismo lugar realizaban su partido de fútbol

\section{La elección espacial}

En las situaciones donde se pudo visualizar que los sujetos ya tenían a priori elegido el espacio para realizar su práctica lúdica se registró que el mismo se desarrollaba como ámbito de convocatoria. El espacio de juego funcionaba como lugar de encuentro y generalmente tenía un horario para el principio y un horario para la finalización. Para los juegos que necesitaban una cancha, 2 o 3 jugadores llegaban antes al lugar y la armaban. En el caso del fútbol se construían los arcos con caños plásticos y sogas y el grupo de 9 vs. 9 pintaba además, los laterales de la cancha con cal.

Para los sujetos que arribaron al parque sin haber elegido a priori el espacio de sus prácticas lúdicas registramos que el mismo espacio seleccionado se va recreando según los juegos que se efectúen. Así visualizamos que una familia se ubicó muy cerca de un "palenque" realizado con los troncos de un árbol. En ese sitio los niños jugaron primero diferentes manchas de persecución teniendo en cuenta el tronco. Luego se dedicaron a pasar el mismo por arriba (se ubicaba a una altura de $50 \mathrm{~cm}$. del pasto) y por último se desplazaron tipo "caballito" recorriéndolo de un extremo al otro.

En otro sector del parque se pudo registrar una familia compuesta por ocho integrantes, entre adultos adolescentes y niños, que luego de conversar y tomar mate realizaron un fútbol entre todos incluidas las mujeres. En ambas situaciones la familia eligió el sitio donde ubicarse, sentarse y dejar sus pertenencias y luego en el espacio disponible se desarrollaron los juegos, aclarando que en el primer caso el mismo espacio se utilizó, se recreó para varios juegos. 
Las principales diferencias entre los sujetos que concurrieron al parque con el espacio, donde realizaron su práctica lúdica, elegido a priori y los agentes sociales que llegaron al parque sin haber seleccionado a priori el espacio que utilizaron para su práctica lúdica son:

1. En las prácticas lúdicas realizadas por los sujetos en forma sistemática se registró la presencia de sujetos que observaban los partidos de voley, fútbol y tejo. Algunos de ellos estaban esperando su turno para jugar, otros solamente miraban los juegos. Había mujeres, niños, jóvenes y adultos. En cambio en las prácticas lúdicas no sistemáticas no existía esta diferencia entre el espacio de juego y el campo de juego. Había una confusión, donde ambos se entrelazaban. Los límites del campo de juego en general no estaban acordados como por ejemplo el joven que lanzaba la pelota de hockey a su perro o el grupo de niños que jugaban a lanzarse un disco volador o frisbee.

2. Los espacios de las prácticas lúdicas realizadas por los sujetos en forma sistemática en el parque Saavedra se pueden considerar como espacios socio recreativos. Los espacios de juego del fútbol, del voley y del tejo se pueden analizar esencialmente través del concepto de amenidad de Atkinson y Robinson citados en Pavía (2005). Conjugan la atracción, el placer con la defensa y preservación del lugar. La realización sistemática de los juegos permite una mayor apropiación del lugar. En el caso de los espacios de las prácticas lúdicas realizadas por los agentes sociales en forma no sistemática se acentúa más la cualidad de lo atractivo y placentero que la formación de deseos de preservación y defensa.

3. Según Pavía (2005) el sitio alude a la condición de espacio perfectamente ubicable y situado, independientemente que alguien lo use y se convierte en lugar a través de un proceso de mayor vinculación de los sujetos con el juego que los convoca. En las prácticas lúdicas realizadas por los sujetos en forma sistemática se pudo observar como los grupos se apropiaron de su lugar. Éste ya estaba elegido a priori y funcionaba como punto de encuentro. En las prácticas lúdicas efectuadas en forma no sistemática no hubo indicio de apropiación del lugar. La práctica lúdica se realizó en forma ocasional y el espacio para efectuarla se eligió una vez que los sujetos arribaron al parque. 
En este capítulo, se llegó a la conclusión que desde un enfoque espacial coincidieron las prácticas lúdicas efectuadas en forma sistemática por los sujetos en el parque con la elección a priori del espacio donde los agentes sociales realizaron sus prácticas lúdicas. Y se pudo comprobar que generalmente coinciden los sujetos que realizan las prácticas lúdicas en forma no sistemática con los sujetos que arriban al parque sin haber elegido a priori el espacio donde realizarán sus prácticas.

En referencia a la elección de los espacios por parte de los sujetos para realizar sus prácticas lúdicas, se determinó que no se elige cualquier espacio sino el que por las cualidades de conjunto favorezca la armonía entre el juego a realizar y el espacio seleccionado.

Según los registros confeccionados, los espacios que elegían los sujetos de las prácticas lúdicas realizadas en forma sistemática se repetían semana a semana lo que facilitaba la construcción de la identidad de ese grupo. En cambio para los sujetos que efectuaban las prácticas lúdicas en forma no sistemática la elección del espacio no pertenecía a una historia grupal o una experiencia anterior sino que era un encuentro ocasional. Los sujetos se ubicaban en el espacio libre que favoreciera la realización de su juego. 


\section{CONCLUSIONES}

De acuerdo a esta investigación pudimos afirmar que existía una relación entre prácticas lúdicas y espacio en un parque público. También, de acuerdo a los registros confeccionados en el Parque Saavedra, identificamos una conexión entre ambos aspectos en las prácticas lúdicas realizadas por los sujetos en forma sistemática y en las prácticas lúdicas efectuadas por los agentes sociales en forma no sistemática.

Parlebas afirmaba que "El espacio material representa el soporte irrecusable de todo juego" (1988: 119). Definir un juego era en parte, establecer las características de los lugares donde se realizaba: dimensiones y normas, naturaleza y consistencia (materiales artificiales, elementos de plena naturaleza). En el Parque Saavedra no se podía concebir la realización de un juego sin un espacio determinado y sin un espacio establecido no se puede efectuar ningún juego.

Williams (1995), geógrafo, citado en Pavía (2005) con su concepto de estructuración de una experiencia recreativa, Alexander (1981) citado en Pavía (2005, proveniente del campo de la arquitectura urbana con el concepto de patrones de acontecimientos, ambos autores con el concepto de carácter de un lugar y Atkinson y Robinson citados en Pavía (2005) con el concepto de amenidad, contribuyeron al abordaje de las prácticas lúdicas desde una perspectiva espacial. Los pensamientos de estos autores, nos permitieron precisar algunos aspectos que consideraban los sujetos, en referencia a la elección del espacio, especialmente en las prácticas lúdicas realizadas en forma sistemática.

Desde una perspectiva espacial

Desde este enfoque pudimos distinguir en el Parque Saavedra, diferentes características en las prácticas lúdicas realizadas por los sujetos en forma sistemática y en las prácticas lúdicas efectuadas por los agentes sociales en forma no sistemática. En relación a los registros confeccionados se observó que los sujetos que realizaban sus 
prácticas lúdicas en forma sistemática estaban inmersos en un proceso de territorialización. Hubo una apropiación del espacio a través del uso sistemático del mismo. Al decir de Pavía (2005) el sitio se convirtió en lugar.

De acuerdo a Delgado Ruiz (2002) la territorialidad remite a la identificación de los sujetos con un área determinada que consideran propia, y que se entiende que ha de ser defendida de intrusiones, violaciones o contaminaciones. En igual sentido se expresan Leanza y Millán (2002) citados por Pavía (2005), quienes esgrimen desde una perspectiva geográfica que la noción de territorio y territorialización se refiere al "conjunto de acciones que en nombre propio llevan a cabo individuos u organizaciones, con la intención de ejercer control, influencia o dominio sobre un área geográfica determinada" (2005: 61).

Bachelard (2012) aporta a través del concepto de topofilia una valoración humana de los espacios de posesión, de los espacios amados, de los espacios defendidos contra fuerzas adversas. Los espacios apropiados por los sujetos que realizan sus prácticas lúdicas en forma sistemática representan algo más que un espacio geométrico, un espacio vacío. La concurrencia semana a semana va configurando un proceso de identidad a partir del concepto de territorialidad. Los sujetos establecieron un espacio considerado como propio, donde ejercían un dominio del mismo y que sería defendido contra fuerzas adversas si fuera necesario. Según Bachelard (2012) el espacio habitado trasciende el espacio geométrico. La vivencia del espacio es parte de la posesión, del espacio amado.

Según los registros confeccionados en el parque Saavedra se pudo establecer que en las prácticas lúdicas efectuadas por los agentes sociales en forma sistemática existía una fuerte vinculación entre los sujetos, inmersos en un proceso de territorialización y los espacios seleccionados para realizar sus prácticas de juego. En cambio, en referencia a los sujetos que realizaban sus prácticas lúdicas en forma no sistemática no construían un proceso de apropiación del espacio a través del uso sistemático del mismo. La realización de la práctica lúdica era ocasional como así también la selección del espacio. Pavía (2005) considera que el lugar connota la relación vincular de los sujetos con el sitio y que es el sujeto el que convierte un sitio determinado en su lugar mediante la ocupación y el uso sostenido y sistemático. En 
este tipo de prácticas no ocurría esta conversión, ya que se efectuaba en forma ocasional.

Considerando a Augé (2007) y Delgado Ruiz M (2002) cabe preguntarse, en futuras investigaciones, si para los sujetos que realizaron sus prácticas lúdicas en forma no sistemática, el Parque Saavedra representaba un "no lugar".

También se pudo apreciar que en un escenario con los mismos atributos materiales los sujetos realizaban diferentes prácticas lúdicas como fue el ejemplo del "palenque". Siguiendo a Calmels (2001) se interpretó, en relación a los juegos de persecución y a las acciones que se realizaban sobre el palenque, que el espacio de juego coincidía con el campo de juego. Es decir que no se habían establecido los márgenes ni límites del espacio utilizado. Un niño podía recorrer el espacio para escaparse de la mancha sin considerar ningún límite. En cambio, en referencia al "fútbol-tenis" los adolescentes habían marcado la cancha y limitado el campo de juego.

En relación a la tensión entre los productores y consumidores de los espacios público planteada por De Certau (1996), en referencia al Parque Saavedra, se registró que los sujetos que realizaron sus prácticas lúdicas en forma no sistemática no respetaron la asignación-función propiciada por los constructores de los espacios del parque. Lo demuestran los ejemplos de los niños que jugaban en los senderos asfaltados como así también los niños y adolescentes que realizaron sus juegos en el "palenque". En cambio los sujetos que realizaron sus prácticas lúdicas en forma sistemática, una vez que seleccionaron su espacio, mantuvieron el mismo en forma reiterada en todos los encuentros, como el ejemplo del fútbol, voley, escuela de tejo y los malabares.

En relación a la temática del espacio, según los registros confeccionados en el parque Saavedra, se pudo observar que hubo sujetos que arribaron al parque con el espacio donde efectuaron su práctica lúdica elegida a priori y otros agentes sociales que concurrieron al parque sin haber elegido a priori el espacio dónde realizaron las mismas. De acuerdo a lo explicitado anteriormente se pudo llegar a la conclusión que, desde un enfoque espacial, coincidieron las prácticas lúdicas efectuadas en forma sistemática por los sujetos en el parque con la elección a priori del espacio, donde los agentes sociales realizaron sus prácticas lúdicas. $Y$ se pudo comprobar que 
generalmente coincidían los sujetos que realizaban sus prácticas lúdicas en forma no sistemática con los sujetos que arriban al parque sin haber elegido a priori el espacio donde efectuaron sus prácticas.

Desde una perspectiva lúdica

En el Parque Saavedra registramos, que las prácticas lúdicas observadas pertenecían al bagaje cultural de los jugadores. Huzinga (2007) consideraba al juego como productor de la cultura y Pavía (2006) señalaba que la mutua influencia entre el sujeto y su contexto posibilitaba la aparición de un modo lúdico producto de la reproducción social y sus diferentes matices. La libertad de elección recibía la influencia del contexto social e histórico. Estas pautas culturales se visualizaron en forma más clara y precisa en los juegos de voley espacialmente en los de la comunidad paraguaya.

En todas las prácticas lúdicas se pudo observar la fuerza incentivadora del juego, es decir, según Pavía (2006), la actitud de cada jugador sumada al deseo y asociada a una manera cultural de jugar. Esta combinación entre actitud y deseo por parte del sujeto y por otro lado la atmósfera particular del juego en lo referido a ser disparador de emociones (no sólo alegría, entusiasmo sino también puede incluir tristezas, decepciones, etc.) conformaban la esencia del juego y lo diferenciaban de otras situaciones de la vida cotidiana.

En todas las prácticas lúdicas registradas en el Parque Saavedra se pudieron reconocer los significados del juego y el jugar aportados por Navarro Adelantado (2002). Especialmente desde la etimología latina del jocus, broma, chanza, diversión y desde el vocablo ludus-ludere que expresa juego infantil, en las acepciones de recreo, competición y juegos públicos. Se pudo visualizar que el juego-jugar mantenía dos rasgos fundamentales a pesar del paso del tiempo: la acción de jugar y la diversiónrecreación.

Se registraron diferencias en relación a lo sistemático de las prácticas lúdicas. En referencia a las prácticas lúdicas realizadas en forma sistemática se observó que los juegos elegidos por los sujetos estaban emparentados con el agón (competición) según la clasificación de Caillois (1958). Fue el ejemplo del fútbol, del voley y de la escuela de tejo. En cambio, en las prácticas lúdicas efectuadas en forma no sistemática se registró 
que los juegos seleccionados estaban más relacionados con el ilinx, vértigo. Fue el ejemplo de los dos adolescentes que se movilizaban en una bobina de cables, de los niños que se trasladaban sentados de un extremo al otro por "el palenque", etc. También se visualizaron prácticas lúdicas orientadas al ludus, dónde los jugadores se plantearon un desafío previo, encontrando la gratificación en la superación del mismo, como por ejemplo el grupo de niños que jugaban a lanzar y a colgar dos zapatillas atadas, a una rama de un árbol.

Un aspecto importante para destacar es que el Parque Saavedra ofrece un espacio apropiado para realizar cualquier tipo de juego en referencia la clasificación de juegos de Caillois (1958), en el ámbito de las prácticas lúdicas realizadas en forma sistemática por los sujetos o efectuadas en forma no sistemática por los agentes sociales.

Los juegos efectuados en las prácticas lúdicas realizadas por los sujetos en forma no sistemática poseían una mayor riqueza y variantes. En el transcurso de las mismas, los sujetos no tuvieron inconveniente en: cambiar de juego, modificar las reglas del mismo, incluir otros jugadores o simplemente dar fin al juego. En cambio, los sujetos que realizaban sus prácticas lúdicas en forma sistemática, fútbol, voley y tejo, ya tenían estipulados: el juego, las reglas del mismo y los horarios de inicio y finalización, variables que no sufrieron modificaciones. En estas situaciones, los aspectos más inciertos, estuvieron focalizados en resolver problemáticas del mismo juego y no orientados a proponer nuevas prácticas lúdicas.

Además pudimos registrar que en las prácticas lúdicas efectuadas en forma no sistemática, los sujetos requerían de un grado mayor de permiso y de confianza, según Pavía (2006), para desplegar sus juegos y que, según Pichón Rivière (1985), el proceso de elaboración de la resistencia al cambio poseía un grado de plasticidad mayor. Los jugadores necesitaban un permiso y confianza para proponer y realizar un juego nuevo o recrear uno viejo y también requerían cierta plasticidad para abordar una resistencia focalizada en efectuar una práctica lúdica inesperada u ocasional.

En las prácticas que se repitieron semana a semana, según las observaciones realizadas los sujetos ya conocían a priori cuál era el juego convocante y generalmente existía una relación vincular entre todos los participantes. Esta situación facilitaba el proceso de permiso y confianza y la resistencia al cambio poseía una menor intensidad. 
Según los registros realizados en el Parque Saavedra, se observó que hubo sujetos que arribaron al parque con el juego seleccionado a priori. Esto implicaba que la convocatoria e invitación se realizó para jugar un determinado juego que ya estaba elegido con anterioridad a la llegada al espacio verde.

Por otra parte, se pudieron registrar los juegos que realizaron determinados sujetos que arribaron al parque sin haber seleccionado el juego a priori. Estos sujetos elegían un espacio del parque para ubicarse, dejar sus pertenencias y luego desarrollaban sus juegos en el espacio circundante. El principio y el final de cada situación lúdica no estaban predeterminados. No seguía un patrón o formato definido establecido con anterioridad.

De acuerdo a lo explicitado anteriormente pudimos concluir al finalizar la investigación que: las prácticas lúdicas que realizaban los sujetos en forma sistemática, es decir aquellas que tenían por lo menos una repetición semana a semana, coincidían con las prácticas lúdicas efectuadas por los sujetos que ya habían elegido a priori su juego.

Del mismo modo se pudo considerar que coincidían generalmente las prácticas lúdicas ejecutadas por los sujetos en forma no sistemática, o sea, que no se registró una reiteración de la misma en una unidad de tiempo semanal, con las prácticas realizadas por los sujetos que arribaron al parque sin haber elegido su juego a priori

A modo de cierre

La investigación podría continuar orientada a los siguientes interrogantes: ¿las prácticas lúdicas que realizan los sujetos en forma sistemática, es decir que se repiten semana a semana, coinciden con los sujetos que arriban al parque teniendo elegido el juego a priori y habiendo definido con anticipación el espacio para realizarlo ?. Y¿̇las prácticas lúdicas que realizan los sujetos en forma no sistemática, es decir que no se repiten semana a semana, coinciden con los sujetos que concurren al parque sin haber elegido el juego a priori y coinciden también con aquellos sujetos que llegan al parque sin haber seleccionado a priori su espacio donde efectuarlo? 


\section{BIBLIOGRAFÍA}

Augé M. (2007) Los no lugares. Buenos Aires, Gedisa.

Bachelard G. (2012) La poética del espacio. México, Fondo de cultura económica.

Buytendijk F. (1935) El juego y su significado. Madrid, Revista de Occidente.

Caillois R. (1958) Teoría de los juegos. Barcelona, Seix Barral.

Calmels, D. (2001), Espacio Habitado. Buenos Aires, Novedades Educativas

Calmels, D. (2003), ¿Qué es la Psicomotricidad? Buenos Aires, Lumen.

Cedeño Perez M. (2005) Relaciones sociales y prácticas de apropiación espacial en los parques públicos urbanos. (El caso del Parc de Les Planes de L'Hospitalet de Llobregat - Barcelona) tesis de doctorado para la obtención del título de Antropología Social para Universidad de Barcelona. Departamento de Antropología Cultural e Historia de América y de África, Barcelona, España http://www.tesisenxarxa.net/TDX-0626108-113928/Universidad de Barcelona.

De Certau M. (1996) La Invención de lo Cotidiano .México, Universidad Iberoamericana.

De Certau M, Girad L, Mayol P. (1999) Capítulo I El barrio .En La invención de lo Cotidiano 2 .México, Universidad Iberoamericana.

Delgado Ruiz M. (2002) Etnografía del espacio público Universidad de Barcelona Revista de antropología experimental, ISSN 1578-4282, $\mathrm{N}^{\circ} .2,2002$ http://dialnet.unirioja.es/servlet/articulo?codigo=276439 
Delgado Ruiz M. (2007) Lo común y lo colectivo. Universidad de Barcelona http://medialab- prado.es/mmedia/0/688/688.pdf.

Elkonin D. (1980).Prólogo y Nota del autor. En Psicología del juego. Madrid, Visor.

Garvey C. (1981) .Capítulo primero: ¿Qué es el juego infantil? En El juego infantil. Madrid. Morata.

Gerlero J. (2004) ¿Ocio, Tiempo libre o Recreación? Neuquén, Educo.

Golbert. (2004)¿Hay opciones en el campo de las políticas sociales? Buenos Aires, Clacso libros.

Guber R. (2001) La etnografía Método, campo y reflexividad. Buenos Aires Grupo editorial Norma.

Huizinga J. (2007), Homo Ludens. Madrid, Alianza / Emecé.

Munné F. (1980) Psicosoicología del tiempo libre. México, Trillas.

Navarro Adelantado, V. (2002) El afán de jugar. Barcelona, Inde.

Parlebas P. (1988) Elementos de Sociología del Deporte. Málaga, Universidad Internacional Deportiva.

Parlebas P. (2001), Juegos, Deportes y Sociedades. Barcelona, Paidotribo.

Pavía, V. (2005) El Patio Escolar: el juego en libertad controlada. Buenos Aires, Noveduc.

Pavía, V. (2006) Jugar de un modo lúdico. Buenos Aires, Noveduc.

Pichón Rivière E. (1985) .El proceso grupal. Buenos Aires, Nueva Visión. 
Pichón Rivière E., Quiroga A. (1999) Introducción. En Psicología de la vida cotidiana. Buenos Aires, Nueva Visión.

Sarlé P. (2006) ¿A qué llamamos juego? Primera parte. En Enseñar el juego y jugar la enseñanza .Buenos Aires, Noveduc.

Tonucci F. (1996) La Ciudad de los Niños .Losada, Buenos Aires. 